NASA/TM-2000-210229

\title{
Performance of an Active Noise Control System for Fan Tones Using Vane Actuators
}

Daniel L. Sutliff

AYT Corporation, Brook Park, Ohio

Alan R.D. Curtis

Materials System, Inc., Littleton, Massachusetts

Laurence J. Heidelberg

Glenn Research Center, Cleveland, Ohio

Paul J. Remington

BBN Technologies, Cambridge, Massachusetts

Prepared for the 6th Aeroacoustics Conference and Exhibit cosponsored by the American Institute of Aeronautics and Astronautics and the Confederation of European Aerospace Societies

Lahaina, Hawaii, June 12-14, 2000

National Aeronautics and

Space Administration

Glenn Research Center 
Available from

NASA Center for Aerospace Information 7121 Standard Drive

Hanover, MD 21076

Price Code: A03
National Technical Information Service 5285 Port Royal Road Springfield, VA 22100 


\title{
PERFORMANCE OF AN ACTIVE NOISE CONTROL SYSTEM FOR FAN TONES USING VANE ACTUATORS
}

\author{
Daniel L. Sutliff \\ Research Engineer, Senior Member AIAA \\ AYT Corporation \\ NASA Glenn Research Center, MS 77-6 \\ 21000 Brookpark Road \\ Cleveland, OH 44135 \\ Alan R.D. Curtis \\ Technology Manager \\ Materials System, Inc \\ 521 Great Road \\ Littleton, MA 01460 \\ Laurence J. Heidelberg \\ Senior Research Engineer, Senior Member AIAA \\ NASA Glenn Research Center, MS 77-6 \\ 21000 Brookpark Road \\ Cleveland, OH 44135 \\ Paul J. Remington \\ Principal Engineer \\ BBN Technologies, Mail Stop 15/2a \\ 70 Fawcett Street \\ Cambridge, MA 02318
}

\begin{abstract}
An Active Noise Control (ANC) system for ducted fan noise was built that uses actuators located in stator vanes. The custom designed actuators were piezoelectric benders manufactured using THUNDER technology. The ANC system was tested in the NASA Active Noise Control Fan rig. A total of 168 actuators in 28 stator vanes were used (six per vane). Simultaneous inlet and exhaust acoustic power level reductions were demonstrated for a fan modal structure that contained two radial modes in each direction. Total circumferential mode power levels were reduced by up to $9 \mathrm{~dB}$ in the inlet and $3 \mathrm{~dB}$ in the exhaust. The corresponding total 2BPF tone level reductions were by $6 \mathrm{~dB}$ in the inlet and $2 \mathrm{~dB}$ in the exhaust. Farfield sound pressure level reductions of up to $17 \mathrm{~dB}$ were achieved at the peak mode lobe angle. The performance of the system was limited by the constraints of the power amplifiers and the presence of control spillover. Simpler control/actuator systems using carefully selected subsets of the full system and random simulated failures of up to $7 \%$ of the actuators were investigated. (The actuators were robust and none failed during the test). Useful reductions still occurred under these conditions.
\end{abstract}

\section{Introduction-}

A goal of the NASA Advanced Subsonic Technology Noise Reduction Program is the reduction in transport aircraft EPNL attributed to the engine source by $6 \mathrm{~dB}$ relative to 1992 technology. A component of EPNL is fan tone noise caused by rotor-stator interaction and duct modal propagation.

A unique characteristic of turbomachinery noise is the modal structure. The acoustic waveform is threedimensional and highly complex, and is best described as a spinning mode ${ }^{l}$. Knowledge of these spinning modes is important to identify the generation mechanism and to successfully apply noise control. Previous work has shown the potential for modal control to reduce the tone levels of ducted fans.

Theoretical and experimental work has shown that Active Noise Control (ANC) can significantly reduce the tone levels of ducted fans. NASA Glenn Research Center's (GRC) Active Noise Control Fan (ANCF) serves as a test bed to verify proposed ANC technologies ${ }^{2.3}$. The tonal nature of rotor-stator 
interaction noise makes ANC a potentially attractive solution. Prior experimental investigations of active noise control used acoustic actuators mounted in the duct walls to reflect or absorb interaction modes ${ }^{4,5}$.

Vane actuators offer a method of applying active noise control at the acoustic source. The unsteady forces of the fan wake passing over the vane and the acoustic sources of the vane actuators are at the same location so there is a potential benefit over active noise control systems that use actuators in the duct walls. Vanemounted actuators require less axial space than an equivalent wall-mounted array, a significant attraction considering the trend toward shorter ducts on turbofan engines. Analytical studies ${ }^{b}$ of the active control of fan noise using vane actuators have suggested that the technique may be feasible.

This report describes an active noise control system that uses vane actuators and the demonstration of the system on the NASA ANCF test rig at NASA GRC. The rotorstator interaction modes at twice blade passing frequency (2BPF) were the target of the active control. The ANCF was configured with 28 vanes to generate the circumferential mode, $m=2$, at $2 B P F$. The $(4,0)$ and (4.1) radials propagated in the inlet and the exhaust over the fan speed range of interest.

A NASA contractor report more fully documents the background and investigation from which this study arose?

\section{Experimental Apparatus}

ANCF Facility

\section{ANCF Test Rig}

The NASA Active Noise Control Fan ${ }^{2}$ rig (figure 1) is located in the Aeroacoustic Propulsion Laboratory at the NASA Glenn Research Center. A sixteen-blade four-foot diameter fan is enclosed in a fan duct that is cantilevered from a support structure. The fan is driven by a shaft that runs through a center body. No internal struts are required since the center body and duct walls are fixed to the support structure. (Internal struts could affect the fan/stator interaction acoustic modes of the duct, resulting in a more complicated mode structure.) Inflow and turbulence distortions that would introduce asymmetric force loading of the blades are minimized by an inflow control device (ICD) at the inlet. A set of stator vanes is cantilevered from a central hub structure.

For these tests, the fan blades were set at an angle of 40 degrees. The twenty-eight stator vanes with the actuator were installed with a 2.25-inch spacing between the fan blades and stator vanes.

\section{In-Duct Measurements}

In-duct levels were measured using the NASA rotating rake modal measurement system that allowed the effect of the ANC on each propagating mode to be independently measured ${ }^{8}$. Time domain averaging is used to reduce noise unsynchronized to fan rotation and narrow band spectra are used to extract the magnitude and phase of each m-order component for each microphone. Different $\mathrm{m}$-orders appear as distinct spectral lines frequency shifted due to Doppler effects. A set Bessel functions appropriate to the $\mathrm{m}$-order is then fitted to the data in a least square sense to obtain the radial mode content. There are two rake microphone arrays for the ANCF, a seven-microphone array for the inlet and a six-microphone array for the exhaust. A gear mechanism rotates the rakes at onehundredth the rate of the fan (only one rake is installed at a time.) The microphone signals are sampled synchronously with the rotation of the fan and hence synchronously with the interaction spinning acoustic modes generated by the fan

The result of the rake processing is a set of complex spinning mode amplitudes at the rake locations ${ }^{3}$. It is assumed that reflections from duct terminations are negligible and that the spinning mode amplitudes represent the amplitudes of modes propagating from fan to the duct termination, and then radiating to the far field.

\section{Far Field Measurements}

Although the reductions of sound level in the fan duct are of significance and provide the primary analysis, the objective of fan noise control is the reduction of the noise radiated to observers in the far field. The ANCF rig was positioned in the center of the anechoic dome in order to measure the farfield directivity. The radiated sound field is measured at an array of 28 microphones placed in the plane of the fan duct and around a semicircle with a radius of 50 feet. Narrow-band spectral analysis was used to detect all tonal components in the sound field at each microphone and BPF, 2BPF and 3BPF components were extracted. The far field data for each harmonic can be used to determine the directivity of the radiation pattern.

\section{Active Noise Control System}

\section{Vane Actuators}

An earlier study evaluated the feasibility of potential actuator technologies for active noise control ${ }^{9}$. This study concluded that although active noise control of fan noise by vane actuators is feasible, no actuator available at the time met the severe noise levels and 
environment requirements of a commercial turbofan engine and that development of such actuators was required.

The requirements for the NASA ANCF are less severe but still demanding. The basic requirement is that the actuator must make enough noise. In order to be able to cancel the sound produced by rotor-stator interaction, the actuator must be capable of making at least the same level of sound. The actuator must also fit within the confines of the vane profile and at least two actuators must be placed across the chord at a given radial location to control two directions. Estimates of the displacements required were available from a simulation of a flat plate cascade model of a vane set using a twodimensional fluid dynamics simulation code.

There are other engineering requirements including cost, reliability, power consumption, structural integrity, environmental requirements including temperature tolerance, and system integration considerations not considered in this investigation.

\section{THUNDER Introduction}

THUNDER $^{10}$ is an actuator technology invented at NASA Langley Research Center. The acronym stands for THin UNimorph DrivEr and sensoR.

A THUNDER actuator is a composite of three thin layers, a metal base, a piezoelectric wafer, and a metal top cover, bonded together under pressure and at high temperature with the LaRC SI polyimide adhesive. When a voltage is applied between the metal layers across the piezo-electric transducer (PZT) it expands, and the differential in-plane stresses cause the actuator to bend or generate a force. The very high bond strength created by the use of the polyimide and the manufacturing process results in a very robust device that can be taken to high strains without fracture. The high displacement capability led to some initial investigations into the feasibility of the use of THUNDER devices as vane actuators for the ANCF.

At the time of the investigation, no physical models of THUNDER actuators were available, and in order to understand the mechanism and properties of the devices, a series of models were constructed and experimentally verified ${ }^{7}$. An understanding of the basic mechanisms allowed educated design of devices to meet a given specification. However, as was discovered early in the development process, the details of each physical device and in particular the method of fixing the device to a support have a great deal of variability that makes accurate prediction of performance problematic.

\section{Actuator Performance Properties}

The drive level dependent properties of the PZT material are apparent when the actuator displacement sensitivities are examined. Figure 2 illustrates this behavior. Figures $2 \mathrm{a}-\mathrm{c}$ are for a prototype actuator close to the final design. Figure $2 d$ shows the vane actuator amplifier output attached to a typical pair of vane actuators.

The capacitance of the PZT material is drive dependent. This behavior can be seen in measurements of actuator dynamic capacitance; that is the measured transfer function between actuator voltage and charge. The dynamic capacitance for a prototype actuator driven at 10 and $100 \mathrm{Vrms}$ at $1000 \mathrm{~Hz}$ doubles from around $70 \mathrm{nF}$ to $140 \mathrm{nF}$. The transducer capacitance increases approximately with the square of the current.

The capacitance non-linearity affects the actuator sensitivity expressed in displacement per volt. Figure 2a shows a graph of displacement output versus voltage drive level for the prototype actuator driven at $1000 \mathrm{~Hz}$. The displacement/voltage sensitivity increases with drive level as the resonance frequency drifts down towards the drive frequency.

PZT is a charge device; an applied charge causes a strain. The piezoelectric sensitivity expressed in terms of displacement/charge is less sensitive to drive level. Figure $2 b$ shows a graph of displacement output versus current drive level. The displacement/current sensitivity is approximately uniform with drive level.

The variation in actuator displacement output resonance with increasing voltage drive level is shown in figure 2c. Note the decrease in resonance frequency with increasing drive level. At high drive levels, this actuator exceeds the design requirement of $25 \mu \mathrm{m}$ rms displacement at $1000 \mathrm{~Hz}$. However, at low levels the resonance frequency is above $1200 \mathrm{~Hz}$, but at high drive levels it has dropped to close to $1100 \mathrm{~Hz}$. Although the increase in displacement due to the presence of the resonance is welcome (as long as all actuators in an array increase by the same amount), the frequency shift has added approximately 45 degrees of phase to the frequency response function. This added phase could cause instability if not modeled by the controller.

At $100 \mathrm{Vrms}$ drive level the sound pressure output was measured at a level of $90 \mathrm{~dB}$ SPL for a $1 \mathrm{kHz}$ sine wave at $1 \mathrm{~m}$ in an anechoic chamber. The total harmonic distortion was less than $26 \mathrm{~dB}$. It is assumed that most of that distortion was due to the power electronics and not non-linearities in the actuator. 


\section{Actuator Geometric Design}

The final actuator design is illustrated in figure $3 \mathrm{a}$. Three PZT-5A tiles each one-inch long, 0.6 inches wide and 0.007 inches thick are bonded to a Beryllium Copper base 1.5 inches wide, 2.5 inches long and 0.010 inches thick. Not shown in the figure are the aluminum top covers for each tile used to maintain flow quality over the cavity. These were 0.001 inch thick and were trimmed to leave a small border at each edge of the tile.

The design of three tiles in one unit was chosen to select the required resonance frequency of $1200 \mathrm{~Hz}$. For the mounting method used, actuators with this geometry have the required resonance for a length of about 1.1 inches, which was a convenient chordwise dimension for an ANCF vane actuator. Experimental experience suggested that actuators with a width-tolength aspect ratio of 0.6:1 performed well. Other aspect ratios either had too much thermal pre-stress curvature or had less repeatable dynamic characteristics. The three-tile design was a method of combining three individual actuators with the right dynamic characteristics to produce one device of the width required for the vane. The small notches in the long sides of the actuator are to relieve the thermal prestress curvature in the long dimension.

Figure $3 \mathrm{~b}$ is cross section of the vane illustrating the installation of the actuators in the vane. The actuator inserted in a pocket machined in the vane and bonded to a small retaining shelf. The actuator operates in dipole mode. radiating sound to both pressure and suction surfaces of the vane. The continuity of airflow over the vane is maintained on each surface by a cover sheet made from perforated metal bonded to the vane so that it conforms to the airfoil profile and lies flush with the surface.

The objective of the ANCF test was to cancel the interaction modes simultaneously in the inlet and exhaust. It is not sufficient for the actuators to be capable of producing the required level of sound: they must be capable of creating the correct mix of modes with the correct phase relationship. It is the phase relationship that is most difficult to meet, and the required actuator outputs may be much larger for a mix of modes with a given phase than the same amplitude of modes with arbitrary phase.

Four actuators per vane are required to cancel the four propagating acoustic modes. The actuator displacement and phase requirements depend on their locations in the vane. In an effort in parallel to the actuator development, the effect on actuator location was studied using VO72" to provided guidance on the final location of the actuators. This rotor-stator interaction noise code accommodates realistic annular geometries. The code was modified to incorporate additional source terms representing the vane actuators. The actuators were modeled as rectangular patches simply supported on four sides with a sinusoidal velocity distribution. These dipole sources were introduced one at a time and used to predict complex transfer functions between the patch velocity and the resulting mode amplitudes.

A matrix of different patch sizes and locations constrained by the physical limitations of the ANCF vane and the prototype vane actuators was run. In order to cancel both inlet and exhaust modes. two different chord-wise locations are required and the geometry of the vane limited the width of the actuators to about oneinch. Wider actuators than this were found less effective. Optimal locations for the chordwise pair were as far apart as possible with one close to the leading edge and the other close to the trailing edge.

For each chordwise location, a pair of spanwise patches were used. These were initially matched to the radial distribution of the disturbance modes. A shorter tip actuator was used to avoid crossing the node of the first radial mode. To compensate, a longer hub actuator was used. Optimal designs tended to make the tip actuator about 2.5 inches long and the hub actuator 5 inches long. For practical reasons, it was desired to have a single actuator design, and so the hub actuator was split into two 2.5 inch devices driven with the same velocity and separated by a suitable gap for the mounting structure. Within these constraints the radial location of the four actuators were varied and a solution with the least maximum displacement required to cancel the expected fan levels was chosen.

A diagram of the locations of the actuators within each vane is shown in figure 3c. Figure $3 \mathrm{~d}$ is a photograph of actuators installed in a vane.

The required four circumferential arrays of actuators were thus constructed from a total of 168 actuators. Each of the 28 vanes held 6 actuators with actuator \#1 being the tip leading edge, \#2 the tip trailing edge, \#3a the middle leading edge, \#4a the middle trailing edge, $\# 3 b$ the hub leading edge and $\# 4 b$ the hub trailing edge. The hub pair of actuators on the leading edge, \#3a and $\# 3$ b, were driven as a pair with the same control signal making effectively one actuator. In a similar way, the inner pair on the trailing edge, \#4a and \#4b, was also driven as a pair giving effectively four independent actuators on each vane. 


\section{Power Amplifier Design}

Power amplifiers were required to drive each of the 168 actuators. Many actuators were driven in pairs by the same control signal enabling actuators pairing at the power amplifiers. This reduced the amplifier requirement to 84 . The two inner actuator pairs on each vane (\#3a\&b and \#4a\&b in fig. $3 c$ ) are required to receive the same control signal so are naturally paired to the output of one amplifier. The outer pair of actuators poses more of a problem, as they are individual devices that receive independent control signals. Due to modal symmetry, an even mode such as $m=4$, actuators in the same location of diametrically opposite vanes receive the same control signal (in fact actuators in every seventh vane receive the same control signal) and it was decided to use these to form a pair at the output of one amplifier channel.

Power amplifiers for PZT actuators such as the THUNDER actuators are a predominantly reactive electrical load; they present the equivalent load of a capacitor to the amplifier. As no commercially available amplifier was available, a custom designed amplifier was built with each amplifier channel designed to drive a pair of installed actuators. The amplifiers are current drive devices, producing a given current output for a given voltage input. The two actuators driven by an amplifier were connected in parallel to the amplifier output to ensure that the full voltage output of the amplifier was applied to each actuator. The amplifier current and voltage output as a function of voltage input when attached to a pair of actuators is shown in figure $2 \mathrm{~d}$. The current output is linear with voltage input; voltage output non-linear.

Current limiting resistors ( $150 \mathrm{mArms}$ rms) were used on the amplifiers to protect the transducers.

\section{Calibration}

In order to prevent control modal spillover, each actuator in an array should have the same sensitivity. Most of the variability in actuator output was reduced by design of the mounting system and by careful control of the manufacturing process. However, as is inevitable, some variation remained.

There were two methods of calibrating installed actuators. Voltage/current ratios were taken as the primary sensitivity measure. A front panel switch on each amplifier rack enabled the monitoring of the voltage and current supplied to the pair of actuators attached to each amplifier channel. The gain of the amplifier from voltage in to current out was trimmed by a potentiometer on the front panel to ensure that each actuator pair in an array received the same current for the same drive signal.

Displacement/current sensitivity is only an indication of the true sensitivity between controller output voltage and the acoustic output of an actuator. An acoustic cavity calibrator was designed, with six microphones in six sealed cavities that could be fixed to the vane. Due to the level dependent sensitivity of the actuators, it is necessary to calibrate the actuators at close to full output power and, although this method allowed an approximate calibration to be performed, acoustic cross-talk between actuators was significant and proved to be sensitive to vane location. A better method would be required if a more accurate calibration were desired. Fortunately, control spillover was low enough for the system to demonstrate reasonable noise reduction levels.

One issue with both the front panel trimming potentiometer and the series trim capacitor is that they limit the maximum output of the actuators. In array of twenty-eight actuators, this means that in order to calibrate the array, all channels have to be reduced to the sensitivity of the actuator with the smallest sensitivity. The maximum output of the array is constrained to the maximum output of the weakest actuator.

\section{Control System}

\section{Controller Requirements}

A typical turbofan engine has many hundreds of acoustic modes that could theoretically propagate. The hundreds of actuators and independent control channels that would be required for a full modal control system would be impractical. Fortunately, the number of modes generated by the fan is usually much less than the total number that could propagate due to the symmetries of rotor-stator interaction ${ }^{1}$. A control system that uses a radially distributed array of actuators can make use of the same geometry to couple into the same set of modes as the fan source, with minimal coupling to any of the other modes. Such a system based on matched symmetrical actuator arrays results in a much simpler controller.

Rotor-stator interaction kinematics allows only certain circumferential mode orders to be generated and propagate. The circumferential mode orders $(m)$ generated are related to the number of fan blades $(B)$, the number of stator vanes $(V)$, and the harmonic $(h)$ of $\mathrm{BPF}$ and are given by the formula:

$$
\mathrm{m}=\mathrm{hB}-\mathrm{kV} \text { ( } \mathrm{k} \text { is any integer) }
$$


An active noise control system must take into account the full set of acoustic modes that it could potentially generate. In order to control any or all of the modes, a modal active control system will require independent control actuator channels equal to the number of modes it is desired to control.

A circumferential array of physically identical actuators with the same axial and radial coordinates can be driven by a single control signal to produce a set of modes with the same circumferential mode order. The signal must be phased shifted appropriately for each actuator position in the array. From the perspective of the controller, the array is a single actuator. However, a problem with such an actuator array is the phenomenon of spatial aliasing. If an array of $L$ actuators is driven to generate a mode order $m$, it will also generate modes of orders:

$$
\ldots, m-2 L, m-L, m, m+L, m+2 L, \ldots
$$

If the highest circumferential mode order that can propagate is $M$, then at least

$$
L>M+|m|
$$

actuators are required to avoid spatial aliasing.

An important observation is that a single actuator array can independently control multiple $\mathrm{m}$ orders when the outputs of two or more phased array signals are summed at each actuator. The number of actuators required is then based on the largest $m$ order required.

If the fan blade and vane counts are chosen such that at most one $\mathrm{m}$ order is cut-on (at least for lower harmonics of BPF), then an array of actuators fully populating the vanes will not alias into cut-on modes as it produces the identical set of aliased modes as the vanes. Reduced actuators arrays, e.g. a set with every other vane containing an actuator, must more carefully consider the aliased modes.

Although the source may only contain modes with one or few m orders, these modes may contain more than one radial order. In order to couple directly with a given $m$ order, a circumferential array must be placed at the same radial location. To control multiple radial orders multiple arrays are required. For the general case, these arrays must be located at either different axial or radial locations.

Arrays placed at the same radial location but different axial locations, for example both on the duct wall, will couple with a given radial order with the same magnitude but different phase. This phase difference is related to the axial phase speed of the mode and is different for different orders. The number of axial arrays required is equal to the number of radial modes propagating in that circumferential mode. By a similar argument, it is necessary to have two sets of arrays at different axial locations to control modes that propagate in the two axial directions, i.e.. the inlet and exhaust ducts.

Similar arguments to those used to specify the actuator requirements apply to specifying the sensor requirements. In general, in order to sense each of the modes of propagation, the same number of independent sensor channels is required. If it is known that only a few independent modes are present, and the mode characteristics are known, then only sensor channels to resolve those modes are required. In theory, these sensors need not be placed in either circumferential or axial arrays; they can be individual sensors with some restrictions on their locations.

\section{Control Strategy for the ANCF Rig}

The control strategy selected for the ANCF was based on the requirements of the specific test conditions. The ANCF is four feet in diameter and has 16 blades. Nominal fan rotational speed is 1886 RPM, resulting in $\sim 500 \mathrm{~Hz}$ BPF tone and $\sim 1000 \mathrm{~Hz} 2 \mathrm{BPF}$. Twenty-eight fan exit guide vanes were selected for the vane actuator tests. The number of stator vanes was selected so that the BPF tone of fan/stator interaction was cut-off. The rotor-stator interaction mode at $2 B P F$ is $m=4$, of which the first two radial modes $(4,0)$ and $(4,1)$ are cuton at $1000 \mathrm{~Hz}$. There are a total of four independent fan modes at 2BPF including modes that propagate both fore and aft.

\section{Actuator Phasing}

The four circumferential arrays of actuators are driven by four independent controller output signals. In order to drive an $m=4$ mode, the signal to each of the 28 vanes in an array must be phased appropriately for the location of the vane. The required increment of phase for an $\mathrm{m}=4$ mode is $2 / 7 \pi$. For each array the actuator in the same vane relative to each quadrant, every seventh vane, will receive the same phased control signal; seven independent signals are required for each control channel and its associated array.

The distribution of the 28 outputs of the actuator array processor to the 84 inputs of the power amplifiers was implemented by distributing the filter outputs to the correct amplifier inputs. Each inner array has two actuators per vane; each inner array control signal drives four amplifier inputs and eight actuators. Outer array control signals drive two amplifier inputs each and four actuators. 


\section{Sensor Arrays}

A set of sensor arrays constructed for this test condition was installed on the ANCF rig. There were six circumferential arrays each of sixteen uniformly spaced sensors: three arrays in the inlet three arrays in the exhaust. The output of these sensor arrays was processed using an analog beam former that observed mode orders $m= \pm 4$.

\section{Tonal Control}

The core control system implements a synchronous multi-channel Filtered-X LMS algorithm ${ }^{12}$. The control and plant filters were three tap digital Finite Impulse Response filters. The plant was identified in the presence of the disturbance in a two step process. The first step designs a set of parallel digital filters that internally cancel the disturbance tone. These filters are then used to detect the increment in residual microphone signals when each of the four actuator arrays is in turn activated by the controller. The controller then designs a set of 24 filters that model the transfer function from each controller output through each actuator array to each microphone array and controller input. The plant identification can also be run with the fan disturbance noise at a different frequency to the actuator drive signals when a function generator is then used to clock the controller.

The core control is then implemented. This is a synchronous adaptive feed-forward scheme based on the Filtered-X LMS. The four output filters were adaptively updated using a function of the output of 24 filters that represent the path from each control output to each sensor input. A feature of the version of the algorithm used for the tests was the ability to set a hard limit to individual control channel output voltages. This was to prevent the control signal from exceeding the maximum level that could safely be accommodated by the power amplifier inputs. The algorithm ensures that the maximum level is not exceeded by preventing any update that would cause a control filter output to exceed that level. The maximum level can be independently set for each control output and if one output is constrained at its maximum, the other control filters can continue to adapt.

A monitor program allows interaction with the controller functions to set filter lengths, convergence parameters and control output limits. It also displays in real time the amplitudes of controller output and residual input signals when the control or identification programs are running.

\section{Control System Schematic}

A schematic of all the control system components and their interconnections is shown in figure 4 .

The control path starts at the sensor arrays. The $6 \times 16$ microphone outputs are processed by the microphone array processor implemented in analog electronics. The six outputs of the array processor represent the $\mathrm{m}= \pm 4$ component of the sound field at each array location. For each array, two possible outputs were available, the cosine transform component or the sine transform component. When added with the correct phase, these two components can be taken as a time domain representation of the $m=4$ component. The six processed sensor signals are filtered by analog antialiasing filters with a cut-off of $1.1 \mathrm{kHz}$.

The controller is implemented on a DSP processor. The control algorithm is a synchronous multi-channel FXLMS with off-line identification in the presence of the disturbance. For the test. a 6 input by 4 output control structure was implemented.

The controller is clocked by a signal derived from a digital encoder on the main fan shaft. The encoder produces $128 \mathrm{TTL}$ pulses per fan revolution. As the fan has sixteen blades, this corresponds to a frequency eight times BPF or four times 2BPF, approximately $4 \mathrm{kHz}$ at $1886 \mathrm{rpm}$. The shaft encoder signal also provided synchronization signals for the rotating rake drive and signal processing system.

The controller is operated in two modes. The first is a synchronous control mode with the fan shaft encoder providing the $4 \mathrm{kHz}$ clock for both controller and rake. The second is an asynchronous control mode with an external signal generator providing the clock for both controller and rake. This second mode is used to measure the output of the control system with the fan operating at a different speed. With the fan 2BPF at a different frequency to the actuators, the effect of the actuators alone can be accurately measured by both the controller and the rake system while the flow effects are still included.

The four analog control output signals are then passed to the digital actuator array processor. This is a bank of 28 digital filters designed to have the correct phase shift to generate four independent $m=4$ mode components at the actuator arrays. The array processor is implemented on DSP computer. No anti-aliasing filters are required, as the control output reconstruction filters suffice. The 28 digital output signals are filtered by a bank of 28 low-pass analog reconstruction filters. 
The 28 analog output signals are then taken to and shared by the appropriate inputs of the power amplifiers. The 84 amplifier outputs are then passed to breakout boards attached above each amplifier rack where calibration trimming capacitors can be attached if necessary. The 168 outputs from the breakout boards go the vane grid where they are distributed to the correct actuators. Twenty-eight fifty-foot long ribbon cables run from the vane grid to a trailing lead and cable attached to each vane.

\section{Results}

$\underline{\text { In-Duct }}$

\section{Actuator Signatures}

The acoustic signature of the actuator system without the acoustic influence of the fan or control system was studied first. This can be done with the fan at zero or very low RPM. However, if the hydrodynamic flow effects are important one can set the fan RPM to about $90 \%$ of the frequency the actuators are driven. This sets up a condition where the actuators see a similar flow field yet their acoustic signature can be easily separated from that of the fan.

Figure 5 shows the modal signature of the individual driver sets. as measured at the inlet entrance plane by the rotating rake. The actuators were driven at $960 \mathrm{~Hz}$. (equivalent to a fan RPM of 1800 ) while the fan rotated at $1650 \mathrm{RPM}$. The 3-dimensional plots show the power in each $(m, n)$ mode. The total PWL in a circumferential mode is shown along the back wall. Indicated in tabular form is the total tone power, the power in $m=4$, and the sum of the power in the non-m=4 modes. These values are an indication of the modal efficiency of the actuators. Ideally, all of the power should be in the $\mathrm{m}=4$ target mode. However, in practice, a system that achieves (1) the target mode $20 \mathrm{~dB}$ higher than the next highest mode and (2) a target mode PWL $10 \mathrm{~dB}$ higher than the sum of all other non-target modes is a realistic goal for near optimum results. (Power in modes other than the target mode is sometimes referred to as spillover.)

Figures $5 \mathrm{a}$ and $5 \mathrm{~b}$ show the leading and trailing edge tip actuators. Most of the power is in mode $(4,0)$. The tip actuators couple best to the outer wall dominated mode. The ratio of $m=4$ PWL to non- $m=4 P W L$ is $6.9 \mathrm{~dB}$ for the leading edge and $5.0 \mathrm{~dB}$ for the trailing edge. While not optimum, these ratios can yield useful results.

The inlet modal signatures of the leading and trailing edge hub mounted actuators are shown in figures $5 \mathrm{c}$ and $5 \mathrm{~d}$. This location couples nearly equally well into the $(4,0) \&(4,1)$ modes. The modal efficiencies of the hub drivers are $17.8 \mathrm{~dB}$ (leading edge) and $9.2 \mathrm{~dB}$ (trailing edge). These ratios are excellent.

The modal signature with all actuator sets driven simultaneously at varying amplifier gain levels is shown in figure 6 . Compare figure $6 \mathrm{~b}$ to figure 5 to compare identical gain settings. Coherently adding the $\mathrm{m}=4 \mathrm{PWL}$ for each of the 4 sets driven individually at a gain of 0.5 (figure 5) yields $104.4 \mathrm{~dB}$. All sets driven simultaneously at a gain of 0.5 yield a measured $\mathrm{m}=4$ PWL at $104.1 \mathrm{~dB}$, as shown in figure $6 \mathrm{~b}$. The individual sets add the target mode coherently as expected.

The spillover measured with all sets driven simultaneously at a gain of 0.5 is $98.1 \mathrm{~dB}$ PWL. Coherently adding the non- $m=4$ PWL from the individual signatures yields $94.2 \mathrm{~dB}$. This is a surprising result in that the extraneous modes would be expected to be random, thus adding non-coherently, let alone greater than the coherent sum. A small mathematical effect could arise from the way the lowlevel modes are analyzed. If a mode is below the measurement floor of $\sim 70 \mathrm{~dB}$ it is not included in the calculation of total PWL. If the individual sets are generating several modes just below this floor, it is possible that all sets combined would raise the PWL to a measurable level. Thus, the individual sets' spillover PWL may be artificially low. Compensating for this by assigning a $70 \mathrm{~dB}$ PWL to all modes not measured yields a total extraneous mode PWL of $95.1 \mathrm{~dB}$ by coherently adding the levels of the individual extraneous modes. This does not explain the entire increase in measured extraneous PWL.

Another possibility that can account for larger spillover is the actuators coupling to each other through the vane. This might change the response of an actuator set when excited simultaneously with other sets compared to its response when excited alone. This type of behavior has been noted in wall actuators. Further testing on actuator-vane-actuator coupling is desirable.

The gain in figures $6 \mathrm{a}-\mathrm{d}$ varies from 0.25 to 1.0 . This corresponds to actuator amplifier output of 42 to $170 \mathrm{mArms}$. The nominal drive level was 0.5 ( $85 \mathrm{mArms})$ and at a gain of 1.0 , audible harmonic distortion was noted, thought to be caused by the current limiting resistors. As the gain is doubled from 0.25 to 0.50 the $m=4$ PWL increases almost $6 \mathrm{~dB}$, as expected. This is expected because a doubling of the gain is approximately a quadrupling of the amplifier power output (see fig $2 \mathrm{~d}$ ). Doubling the gain again (to 1.0 ) increases the PWL by only $3 \mathrm{~dB}$. This non-linear 
response is further indication of the distortion. Most of the distortion at the higher gain settings was noted to be into the harmonics. The modal efficiency measured at each gain setting is approximately $6.0 \mathrm{~dB}$, nearly independent of gain setting.

Figure 7 shows modal signature of the actuator sets excited individually as measured by the rotating rake at the exhaust exit plane. While the inlet and exhaust rake data are not taken simultaneously, the actuator inputs were the same for the two runs so the signatures can be considered as the overall signature. The $m=4$ PWLs are generally lower in the exhaust than in than those measured in the inlet, indicating the actuators radiate more toward the inlet.

The tip leading edge set (fig. $7 \mathrm{a}$ ) has a very poor modal signal-to-noise ratio, $0.7 \mathrm{~dB}$. This is due to the low $\mathrm{m}=4$ output level generated by this set rather than a high level of spillover. The tip trailing edge and hub leading edge ratios are good at 8.3 and $8.5 \mathrm{~dB}$ (fig. $7 \mathrm{~b}$ and $7 \mathrm{c}$ ). The hub trailing edge actuator set is particularly efficient with a $12.9 \mathrm{~dB}$ ratio (fig. d).

Figure 8 shows modal signature in the exhaust generated by all actuator sets driven simultaneously, at various amplifier gains.

Comparing the coherently added $m=4$ PWLs noted in figure 7 to the level actually measured yields $99.9 \mathrm{Vs}$ $100.5 \mathrm{~dB}$. Again the extraneous modes are for the combined excitation are higher than expected, $97.7 \mathrm{~dB}$ measured vs. $90.9 \mathrm{~dB}$ from the coherently added sum (94.1 dB if modes below the floor are mathematically added). The same argument is made for the exhaust observations as was made earlier with the inlet results.

Figure $8 \mathrm{a}$ and $8 \mathrm{~b}$ indicate that doubling the input gain also causes a $6 \mathrm{~dB}$ increase in the mode PWL, with further increases in gain in figure $8 \mathrm{c}$ exhibiting the amplifier output limit.

\section{ANC Performance}

The in-duct performance of the ANC system was judged by two criteria. The first is the ability of the system to reduce the level of the target mode. This is an evaluation of the quality of the convergence algorithm and the input sensor's ability to distinguish the target mode. The second is the reduction achieved in the total harmonic tone power level. This is primarily related to the modal efficiency of the actuators as described in a previous section.

The ANC performance at a corrected fan speed of 1800 RPM is presented in figure 9. Figure 9a shows the inlet modal map of the fan at $2 \mathrm{BPF}$. The two radials $(4,0)$ and $(4,1)$ of the rotor-stator interaction mode are clearly seen. The $m=4$ PWL is $108.4 \mathrm{~dB}$ and very weak extraneous modes are seen.

The modal map with the ANC system active is shown in figure $9 \mathrm{~b}$. The $\mathrm{m}=4$ mode has been reduced $7.6 \mathrm{~dB}$. The total 2BPF PWL has been reduced $6.2 \mathrm{~dB}$. The difference is a result of the ANC system increasing the level of the non- $m=4$ modes by $3.3 \mathrm{~dB}$. The equivalent performance in the exhaust is shown in figure $9 \mathrm{c}$ and $9 \mathrm{~d}$. The $\mathrm{m}=4$ mode has been reduced by $3.7 \mathrm{~dB}$, with a total PWL reduction of $2.0 \mathrm{~dB}$. At first glance, it appears that the inlet performance is superior. However, the controller works to reduce all the input sensor channels to a minimum in a total RMS sense. This control methodology tends to equalize the inlet and exhaust $m=4$ levels which are 100.8 and $101.9 \mathrm{~dB}$, respectively. The remaining difference might be attributed to the difference in the duct geometry.

Figure 10 shows that the performance of the ANC system is maintained over a fan corrected RPM range of 1400 to 1800 . Figure $10 \mathrm{a}$ compares the individual radial mode absolute levels of the fan to levels with the ANC operating. The reduction achieved for the individual modes are shown in figure $10 \mathrm{~b}$. For fan speeds above 1550 RPM where two radials are present, a 6 to $8 \mathrm{~dB}$ of reduction in $m=4$ is achieved Most of the mode reduction is due to a reduction in the $(4,1)$ radial as it is generally the strongest radial present in the original fan signature. The apparent increase in performance at 1500 RPM and below is a result of the (4,1) mode cut-off resulting in an over-specified control system. The additional flexibility results in a complete cancellation of the $(4,0)$ mode.

A modal noise floor is calculated by mathematically removing the $m=4$ from the fan $2 B P F$ mode map illustrated in figures 5-9. This can be considered the maximum theoretical performance of the ANC system for that particular speed. Figure $10 \mathrm{c}$ shows the absolute levels of the tone are brought down to the modal floor levels when only a single radial is present. When the second radial is cut-on, the system does not achieve the full reduction possible. This is partly due to the power amplifiers limits mentioned earlier. Figure 10d shows the reduction achieved in the 2BPF tone level. About 4 to $6 \mathrm{~dB}$ in tone reduction is achieved when two radials are present, up to $14 \mathrm{~dB}$ when only a single radial is present.

The corresponding solutions for the exhaust are shown in figure 11. The $m=4$ levels shown in figure 11 a are reduced to approximately those in the inlet as a result of the controller reducing the error levels in a RMS sense. However, the reduction achieved is in the exhaust is lower, ranging from 2 to $4 \mathrm{~dB}$ as can be seen on 
figure $11 \mathrm{~b}$. In some cases the $(4,0)$ radial is actually increased but since it was 10 or more $\mathrm{dB}$ below the (4,1) radial, this does effect the over-all result in an acoustic sense.

Figure 11c shows the levels in the exhaust are not driven to the optimum levels. Approximately 2-3 dB total 2BPF tone PWL reduction is achieved in the presence of two radials, $14 \mathrm{~dB}$ with only the $(4,0)$ radial present (figure $11 \mathrm{~d}$ ). The radial mode phasing required to achieve reduction resulted in the amplifier limiting the magnitude.

Of reasonable concern is the complexity of this or any current ANC concept, along with the robustness of the system, particularly of actuators. (None of the actuators failed during the test). The ANC system output channels were reduced to demonstrate the performance of an under-specified system. The input channel architecture was kept the same. Figure 12 shows the performance with reduced actuator channels for a single fan speed.

In figure 12a, the performance in the inlet for cases where only the leading edge pairs, trailing edge pairs. or the tip pairs of actuators are used is compared to the baseline case (all actuators). Since $1 / 2$ of the actuators were used performance with the reduced sets driven at double the gain is also shown for comparison. The most effective actuator set in the inlet is the trailing edge set, obtaining 5.8 of the $9.5 \mathrm{~dB}$ obtained using all actuators. The tip actuators do not couple well to the fan modes when used alone. This is not surprising since the source is known to be distributed radially.

Actuator failure might occur at various points in the system. One failure was represented by a removing system channel 1 , which resulted in a loss of 12 specific actuators tied to that channel. This resulted in a reduction of $4.7 \mathrm{~dB}$ compared to the full system reduction of $9.5 \mathrm{~dB}$. A second type of failure was represented by nulling 8 random pairs of actuators, which yielded $4.0 \mathrm{~dB}$ of reduction. The number of actuators 'lost' could be considered extreme yet useful reductions still occurred.

Figure 12b shows that the exhaust the leading edge was the optimum under-specified set. The fact that the inlet and exhaust had a different optimum set may indicate that a location nearer to the mid-chord may result in a set that is optimum for both directions. The performance of the 'failures' in the exhaust was approximately the same as was noted in the inlet.

\section{Farfield Results}

Farfield directivity for the corresponding 1800 RPM $A N C$ run is shown in figure 13 . A reduction of $13.5 \mathrm{~dB}$ SPL at $41.5^{\circ}$ and 12.8 at $74.5^{\circ}$ occurred. Those angles correspond to the $(4,0)$ and $(4,1)$ lobe peaks.

The 2BPF tone PWL was calculated by integrating the SPL at the single azimuthal angle over a sphere. This method can introduce errors from circumferential modal interference pattern that varies with azimuthal angle under certain conditions ${ }^{13}$. The integration was arbitrarily divided at $90^{\circ}$ to obtain the PWL in the forward and aft quadrants. These results of these calculations are shown in figure 14. A farfield reduction of approximately $4 \mathrm{~dB}$ PWL is achieved over the RPM range. At 1500 RPM a $2 \mathrm{~dB}$ increase was measured. However, the 1500 RPM speed was noted to unique with respect to the cut-on of $(4,1)$ and this might explain the increase. Significant reduction is measured at 1400 RPM where only a single radial exists occurs; as was noted in-duct.

\section{Conclusion}

An active control system for ducted fan noise that uses vane actuators has been shown to be feasible. The vane actuator ANC system reduced total power levels in the target modes by up to $9 \mathrm{~dB}$ in the inlet while at the same time exhaust power levels were reduced by up to $3 \mathrm{~dB}$. The reduction in the $2 B P F$ tone PWL achieved was 6 and in the inlet and $4 \mathrm{~dB}$ in the exhaust. $A$ simplified control system with just two actuator arrays at different radial locations was demonstrated to simultaneously reduce tonal power in both inlet and exhaust. The performance of the simplified control system worked well.

The requirements of a vane actuator for the ANCF were a device that could be installed in a vane and produce displacements of over 0.001 of an inch at $1 \mathrm{kHz}$. An actuator based on THUNDER technology was built that met these requirements. A total of 168 actuators were installed in 28 vanes. They proved to be very robust, none of the actuators failed during the six weeks of testing. The sensitivity of the actuators was uniform across the batch; with minimal calibration control modal spillover was kept to around $-10 \mathrm{~dB}$.

The control system tested did not have sufficient control authority to reduce the level of the $2 \mathrm{BPF}$ tone to the level of the broadband background. The main cause of this was power amplifiers were conservatively 
current limited to $150 \mathrm{mArms}$ to protect the actuators. The vane actuators are believed to be able to withstand in excess of $200 \mathrm{mArms}$. With these higher drive levels, the vane actuators should have had sufficient authority to further reduce the ANCF tones.

The second limitation on performance was spillover. The ability of the actuator arrays to control the fan interaction modes was reduced by the difference in sensitivity of the elements of the array. In this test, only minimal calibration of the actuators was done, as exact acoustic calibration was problematic. The acoustic calibration device designed for the vane actuators proved to be difficult to use and suffered from acoustic cross talk between microphone cavities. As the performance of the system in terms of the objectives of these tests was acceptable, no attempt was made to improve the calibration (this is best done on individual vanes before installation in the duct). It is reasonable to assume that some system performance would ensue from improvements to both the manufacturing batch uniformity and to the acoustic calibration procedure.

The difference in relative performance in the exhaust duct did not seem to be due to lack of control authority or control spillover in the exhaust. This is certainly partly due to the lower power levels in the exhaust; a least squares control system will tend to equalize levels between inlet and exhaust. An additional effect maybe the fan duct convergence that occurs just before the exit plane where the center body increases in size from a hub tip ratio of 0.35 to 0.5 . The axial phase speed of the fan interaction modes will vary as they propagate through this section and perhaps they mix in some unmodeled way at the exhaust sensor arrays. As real engine ducts have similar transitions in cross section, further investigation of the cause of this problem is justified.

Selected subsets of the actuators were run to determine the feasibility of reducing the system complexity. The results indicated that a correctly placed pair of control actuator arrays might couple to these four modes in a similar way, enabling two actuator arrays to control four modes. As engine applications have many fan interaction radial mode components, this efficiency of vane actuators could prove to be necessary for the practical application of ANC.

Analysis of simulated failures shows that a useful amount of reduction occurs even with multiple actuator failures.

A benefit of vane actuators is that they act at the source of the disturbance. If both fan interaction and control sources are at the same location and are both dipole sources, then they should couple with the duct acoustics in the same way. From a small defined region, the fan interaction generates, and the actuators couple to, four independent acoustic modes, two in the inlet and two in the exhaust. Similar coupling by a series of wall actuator arrays may require prohibitive duct length.

\section{References}

1 Tyler, J.M., and Sofrin, T.G., "Axial Flow Compressor Noise Studies," SAE Transactions, Vol. 70, 1962, pp. 309-332.

2 Heidelberg, L.H., Hall, D.G., Bridges, J.E., and Nallasamy, M., "A Unique Ducted Fan Test Bed for Active Noise Control and Aeroacoustics Research," NASA TM-107213, May 1996, also AIAA Paper 96-1740 May 1996.

3 Sutliff, D.L., Nallasamy, M., Heidelberg, L.J., and Elliott. D.M, "Baseline Acoustic Levels of the NASA Active Noise Control Fan Rig," NASA TM-107214, May 1996, also AIAA-96-1745, May 1996.

4 Sutliff, D.L., Hu, Ziqiang, and Pla. Frederic G., "Active Noise Control of Low Speed Fan Rotor-stator Modes," NASA TM-107458, May 1997, also AIAA-97-1641, May 1997.

5 Thomas, R.H., Burdisso, R.A., Fuller, C.R. and O'Brien W.F., "Active Control of Fan Noise from a Turbofan Engine", AlAA Journal 1994, 32(1) p23-30.

6 Kousen, K.A., and Verdon, J.M., "Active Control of Wake/Blade-Row Interaction Noise," AIAA 93-4351 1993.

7 Curtis, Alan R. D., "Active Control of Fan Noise by Vane Actuators," NASA/CR-1999-209156.

8 Heidelberg, L.J., and Hall, D.G. "Inlet Acoustic Mode Measurements Using a Continuously Rotating Rake," Journal of Aircraft, 32(4), p761-767, 1995.

9 Simonich, J.C., "Actuator Feasibility Study for Active Control of Ducted Axial Fan Noise," NASA Contractor Report CR-195412, May 1995.

10 U.S. Patent No. 5632841, Thin layer composite unimorph ferroelectric driver and sensor, May 27, 1997.

11 Meyer, H.D. and Envia, E., "Aeroacoustic Analysis of Turbofan Noise Generation," NASA CR-4715. March 1996.

12 "Algorithm for Multichannel LMS Adpative Filtering," Electronics Letters 21 979-981 1985.

13 Heidelberg, L.J., Sutliff, D.L., and Nallasamy, M., "Azimuthal Directivity of Fan Tones Containing Multiple Modes," NASA TM-107464, May 1997, also AIAA-97-1587, May 1997. 


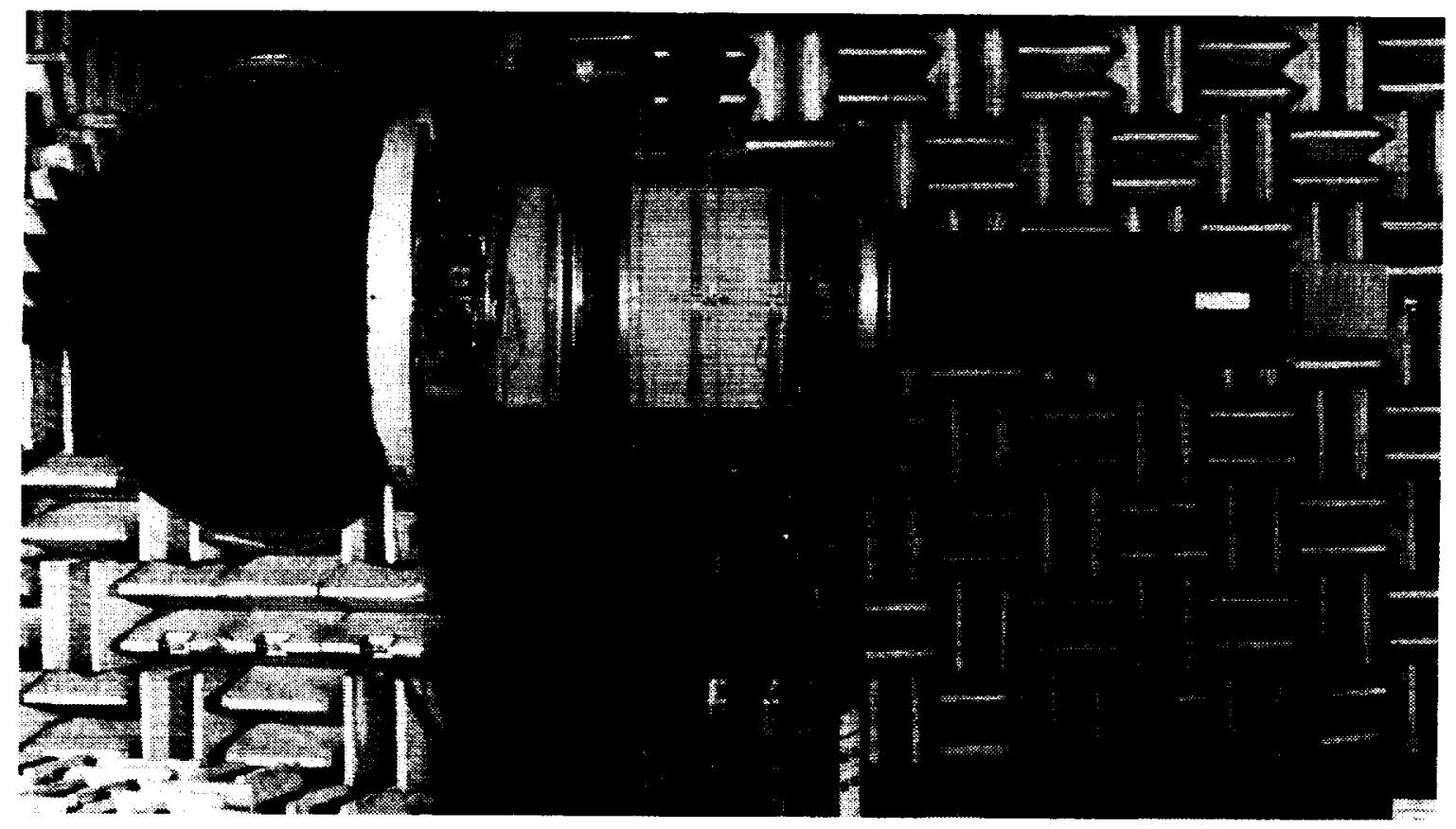

a) ANCF Side View

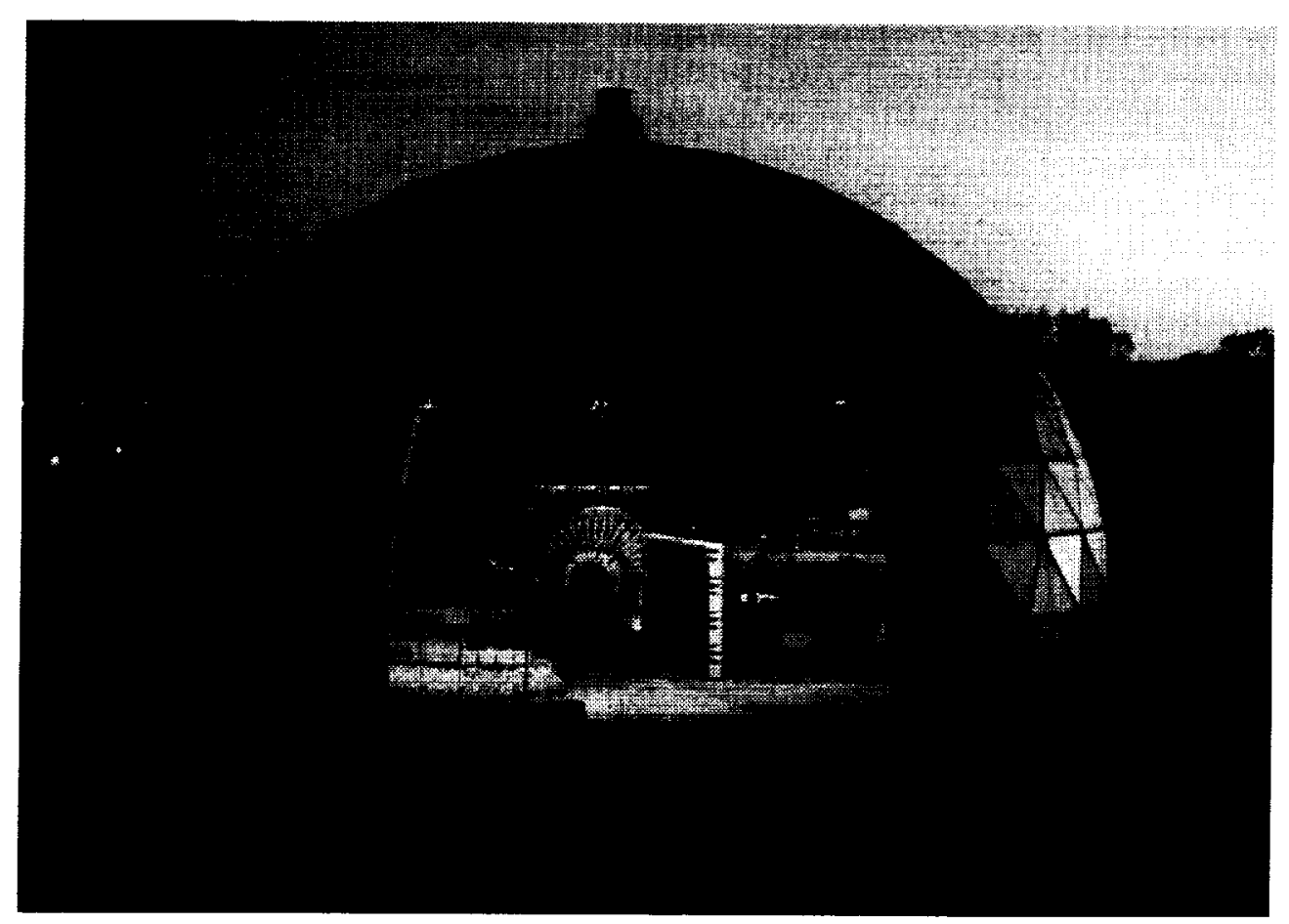

b) ANCF located in AAPL Dome

\section{Figure 1. Photos of Active Noise Control Fan}




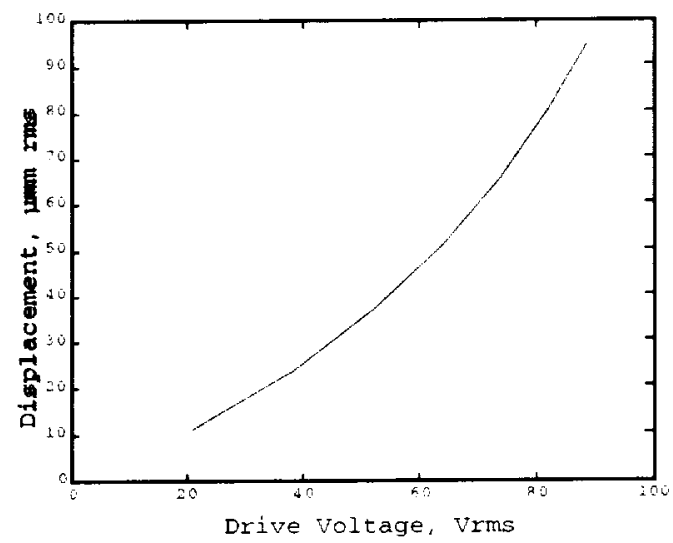

a) Displacement ys Voltage

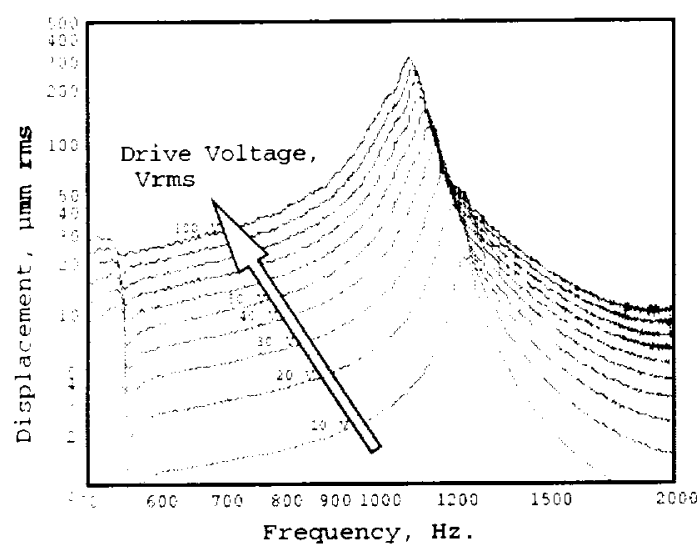

c) Actuator Displacement vs Erequency

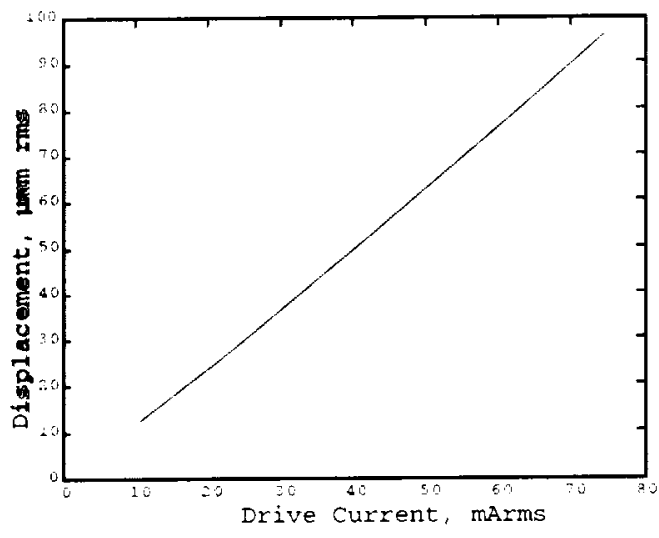

b. Displacement us Current

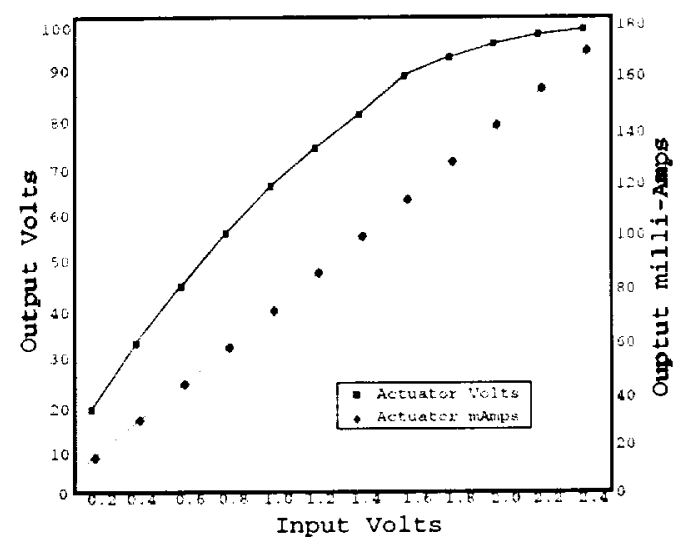

d) Actuator Amplifier Output

Figure 2. VaneActuator Performance 


\section{an}

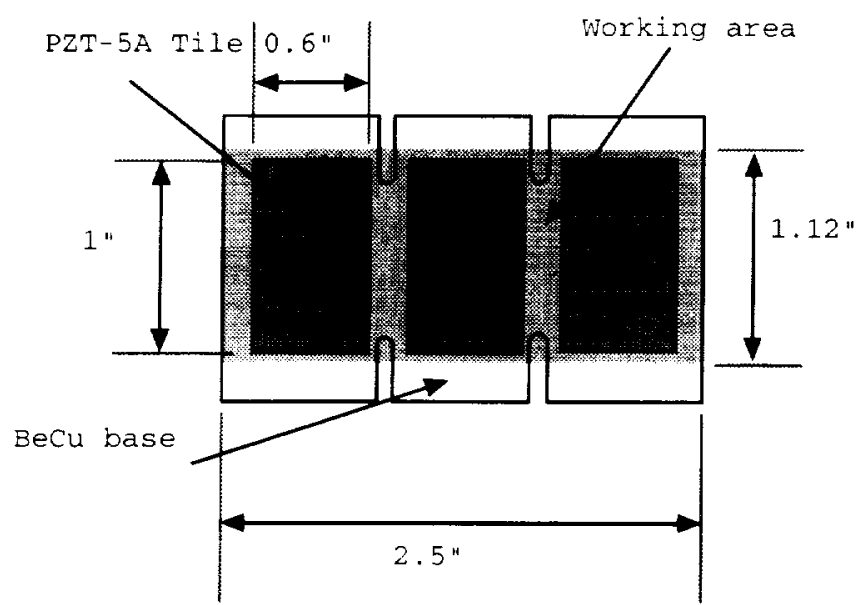

a) Actuator Final Design

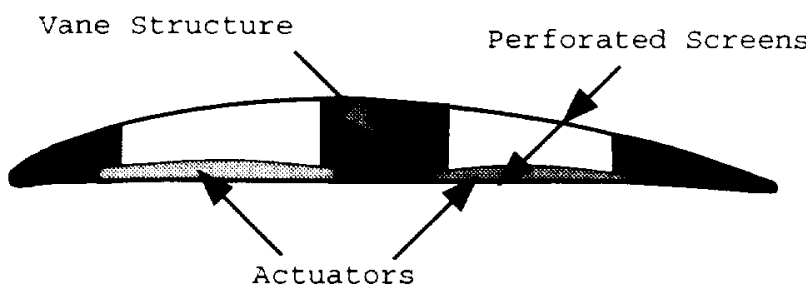

b) Actuator Vane Installation

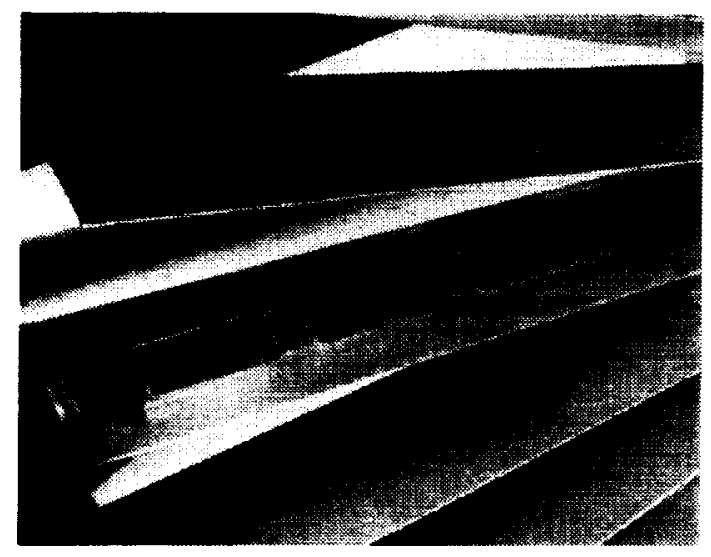

suction side

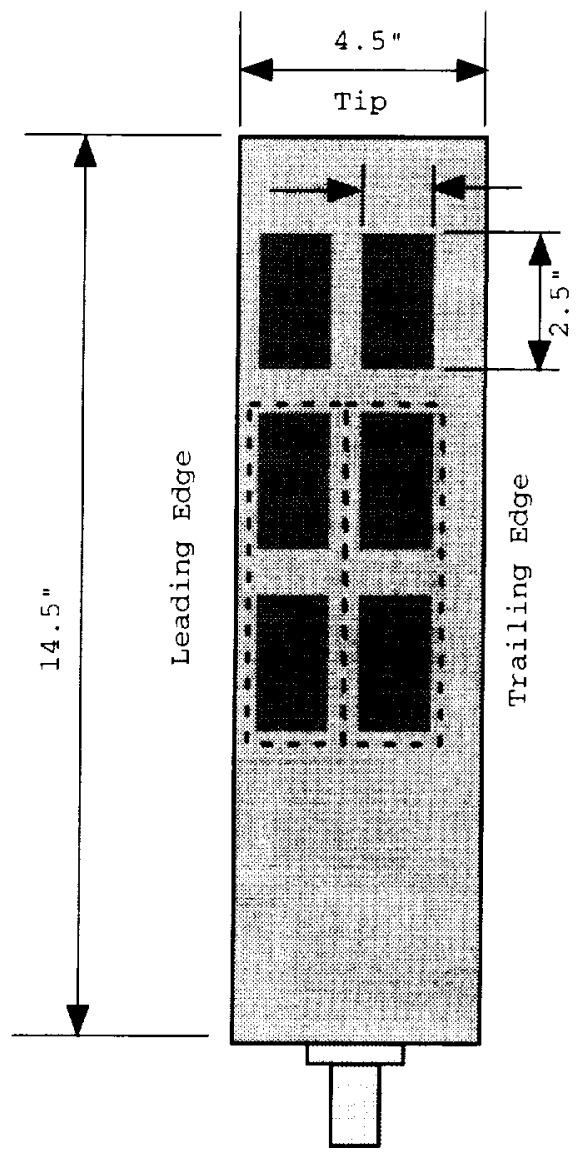

Hub c) Schematic of Actuators in Vane 


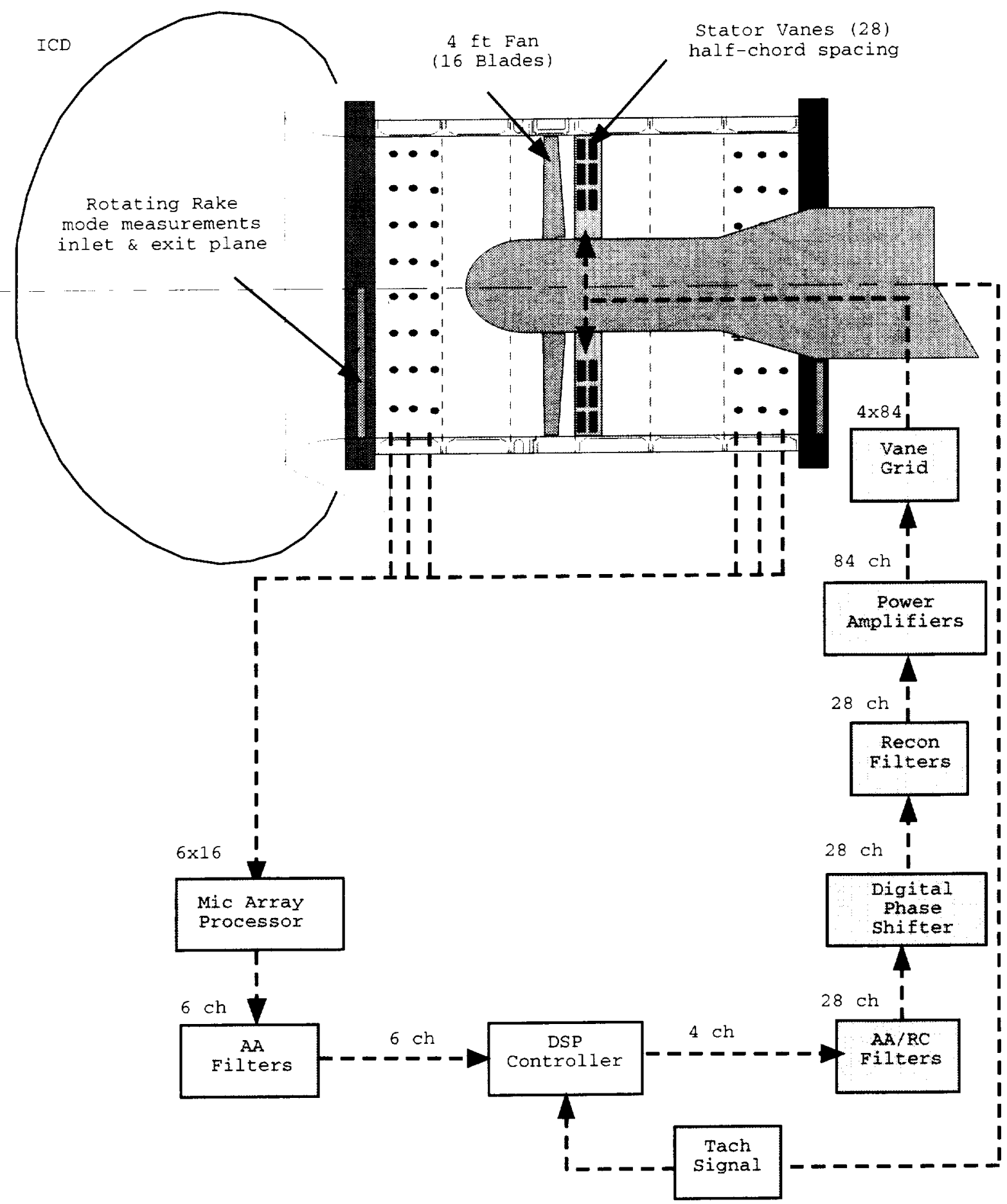

Figure 4. Schematic of ANCF Test Rig with ANC Block Diagram 
NASA ANCF 48" Fan Mode Power Levels

28 Vanes @ $2.25 " * \quad=1650$

Rake a inlet entrance plane

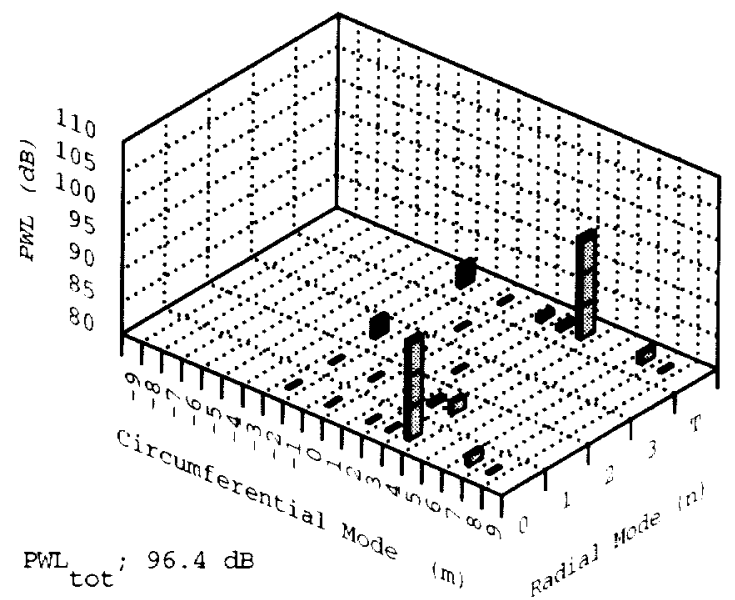

$\mathrm{m}=4 ; 95.6 \mathrm{~dB}$

non $\mathrm{m}=4 ; 88.7 \mathrm{~dB}$

a) Tip Leading Edge

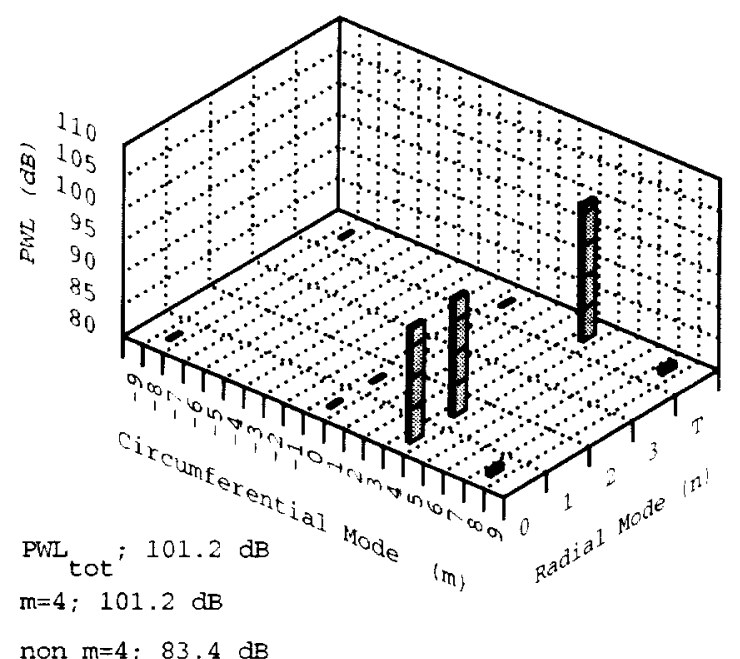

non $\mathrm{m}=4 ; 83.4 \mathrm{~dB}$

c) Hub Leading Edge
Sets Actuated Individually

non-synchronous to fan

Amplifier Gain $=0.5$

$$
f=960 \mathrm{~Hz} \text { (eq } 2 \mathrm{BPF} \text { * }=1800 \text { ) }
$$

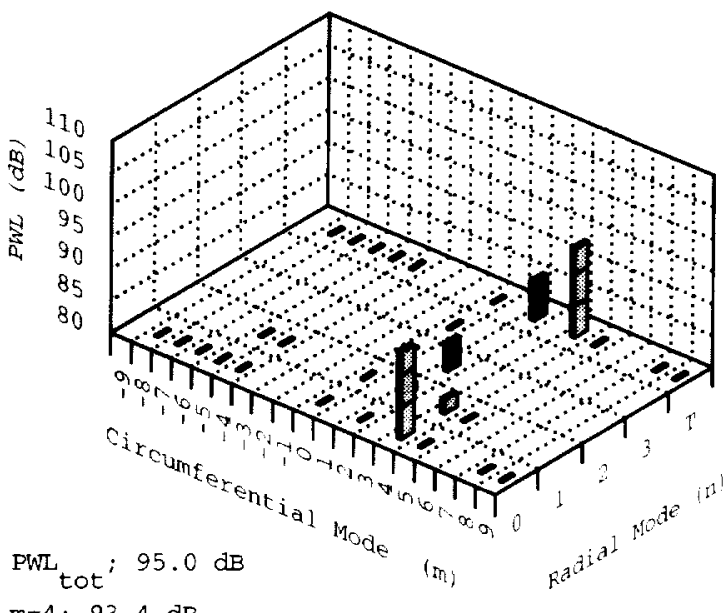

$\mathrm{m}=4 ; 93.4 \mathrm{~dB}$

non $\mathrm{m}=4 ; 88.4 \mathrm{~dB}$

\section{b) Tip Trailing Edge}

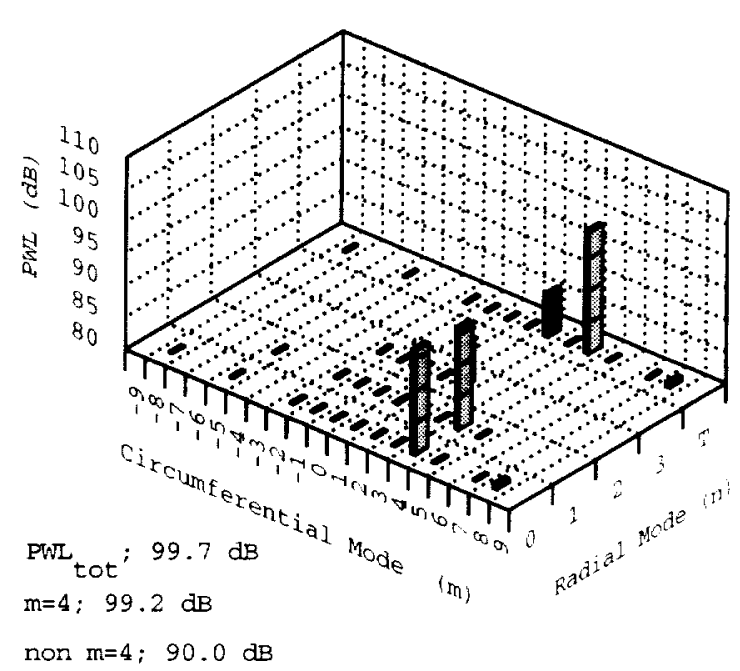

d) Hub Trailing Edge

Figure 5. Individual Actuator Signatures in Inlet 
NASA ANCF 48" Fan Mode Power Levels

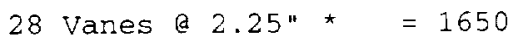

Rake @ inlet entrance plane

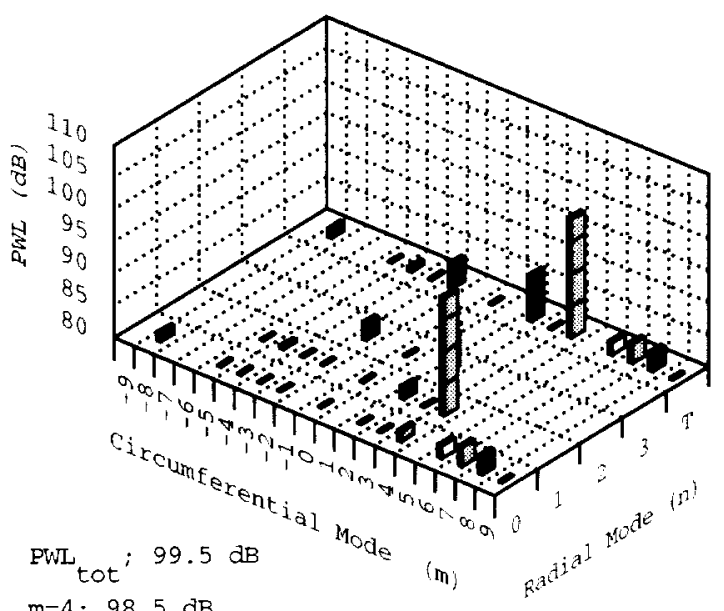

$\mathrm{m}=4 ; 98.5 \mathrm{~dB}$

non $m=4 ; 92.6 \mathrm{~dB}$

a) Amplifier Gain $=0.25$

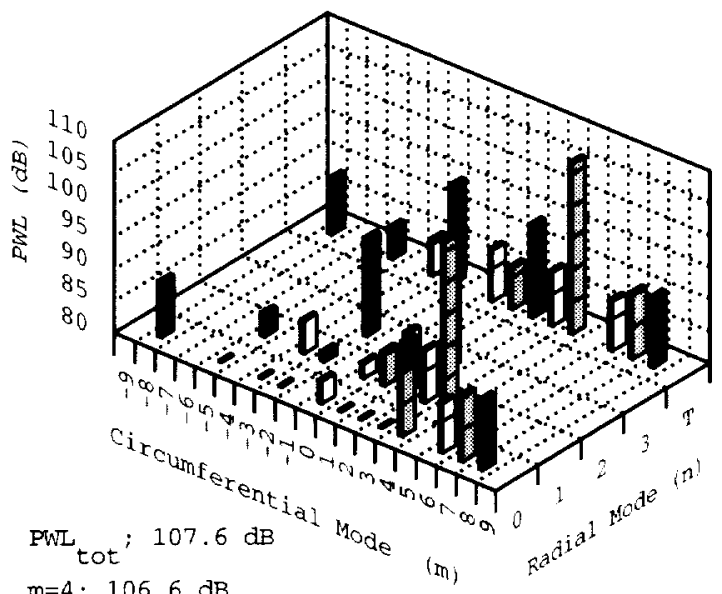

$\mathrm{m}=4 ; 106.6 \mathrm{~dB}$

non $\mathrm{m}=4 ; 100.8 \mathrm{~dB}$

c) Amplifier Gain $=0.75$
Sets Actuated Simultaneously

non-synchronous to fan

Amplifier Gain Vary

$f=960 \mathrm{~Hz}(\mathrm{eq} 2 \mathrm{BPF}$ * $=1800)$

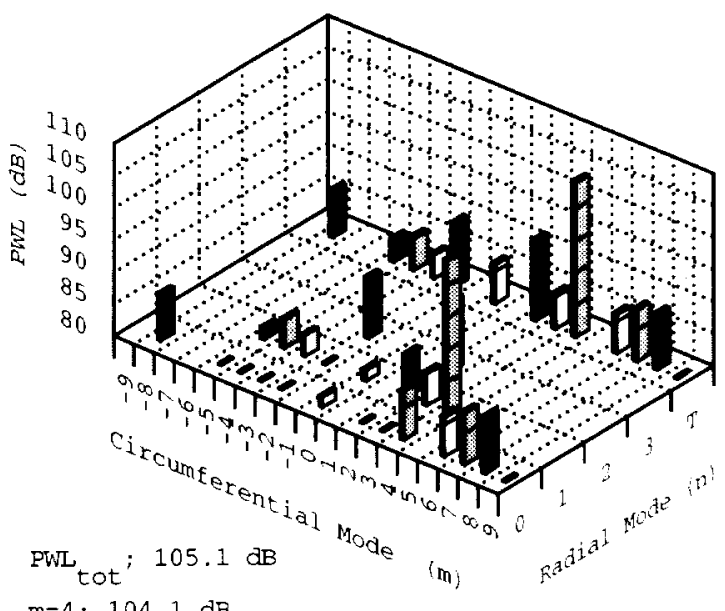

$\mathrm{m}=4 ; 104.1 \mathrm{~dB}$

non $\mathrm{m}=4 ; 98.1 \mathrm{~dB}$

b) Amplifier Gain $=0.50$

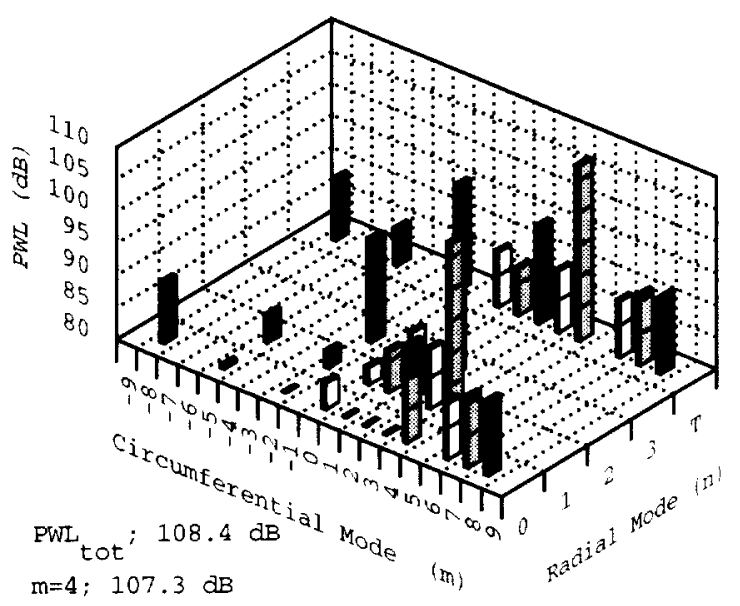

non $\mathrm{m}=4 ; 101.6 \mathrm{~dB}$

d) Amplifier Gain $=1.00$

Figure 6. Combined Actuator Signatures in Inlet 
NASA ANCF 48" Fan Mode Power Levels

28 Vanes a $2.25 " *=1650$

Rake @ exhaust exit plane

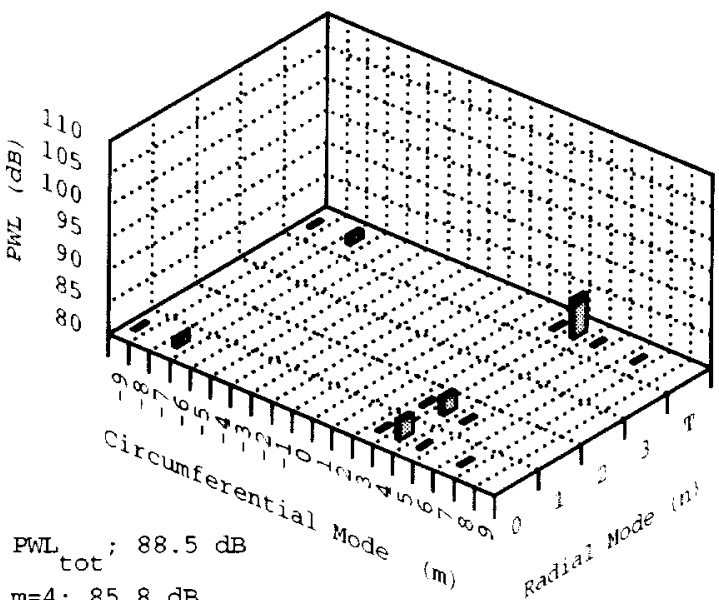

$\mathrm{m}=4: 85.8 \mathrm{~dB}$

non $\mathrm{m}=4 ; 85.1 \mathrm{~dB}$

a) Tip Leading Edge

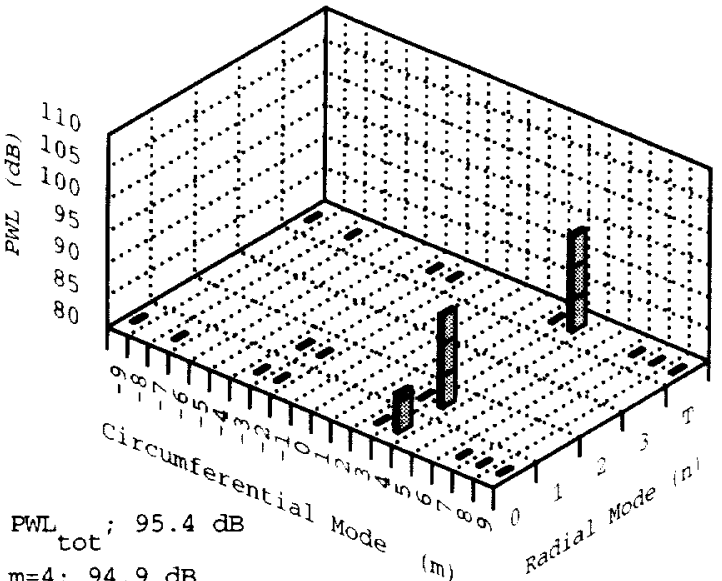

$m=4 \cdot 94.9 \mathrm{~dB}$

non $\mathrm{m}=4 ; 86.0 \mathrm{~dB}$
Sets Actuated Individually

non-synchronous to fan

Amplifier Gain $=0.5$

$f=960 \mathrm{~Hz}($ eq $2 \mathrm{BPF} * \quad=1800)$

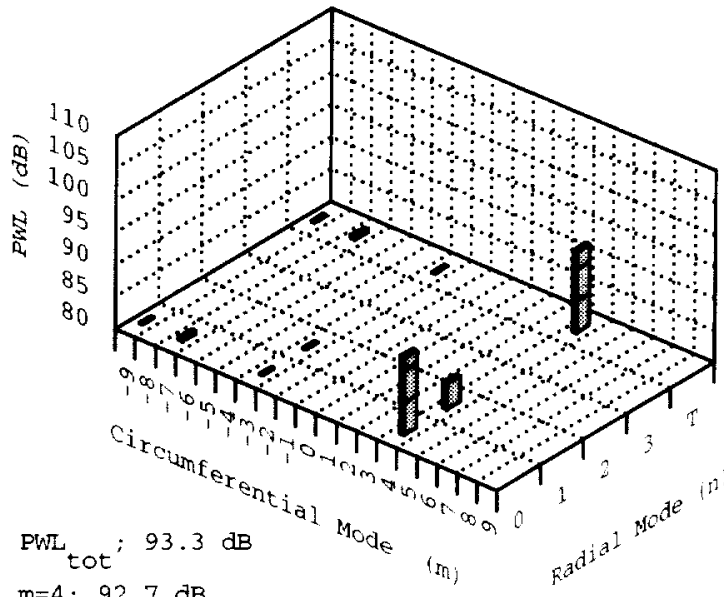

$\mathrm{m}=4 ; 92.7 \mathrm{~dB}$

non $\mathrm{m}=4 ; 84.4 \mathrm{~dB}$

b) Tip Trailing Edge

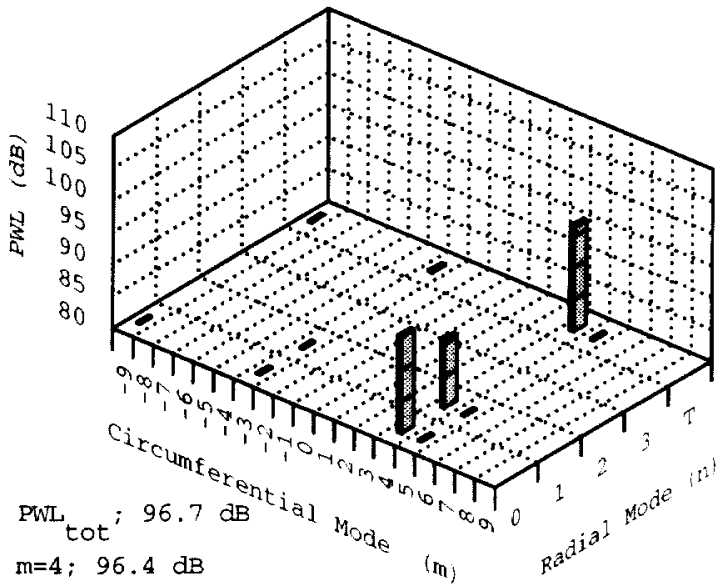

non $\mathrm{m}=4 ; 83.5 \mathrm{~dB}$

d) Hub Trailing Edge

c) Hub Leading Edge

Figure 7. Individual Actuator Signatures in Exhaust 
NASA ANCF 48" Fan Mode Power Levels

28 Vanes @ 2.25" * $=1650$

Rake @ exhaust exit plane

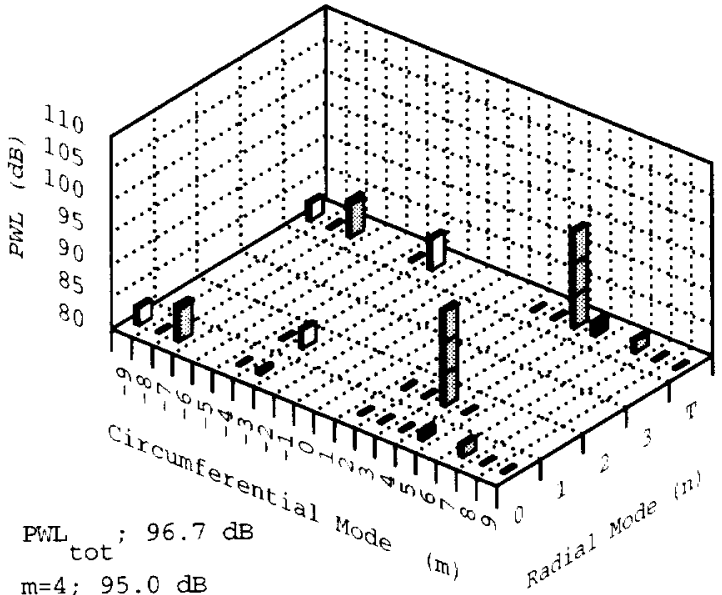

$\mathrm{m}=4 ; 95.0 \mathrm{~dB}$

non $\mathrm{m}=4 ; 91.8 \mathrm{~dB}$

a) Amplifier Gain $=0.25$

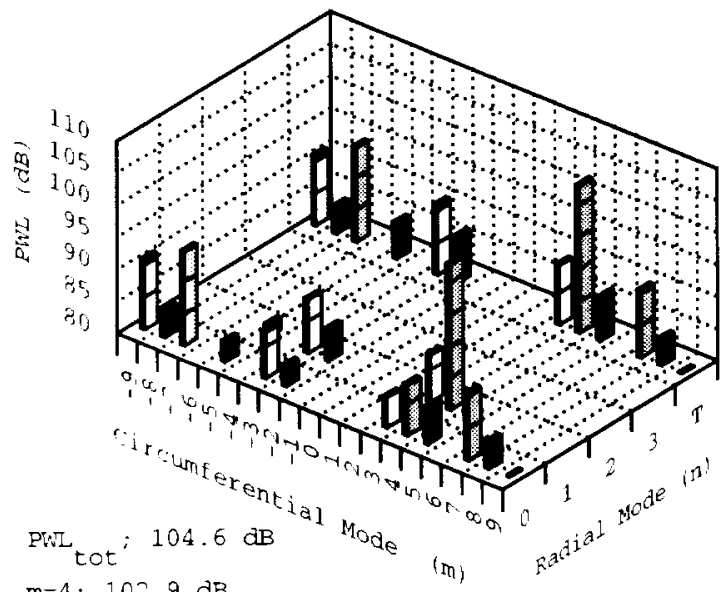

$\mathrm{m}=4: 102.9 \mathrm{~dB}$

non $\mathrm{m}=4 ; 99.6 \mathrm{~dB}$

c) Amplifier Gain $=\mathbf{0 . 7 5}$
Sets Actuated Simultaneously

non-synchronous to fan

Amplifier Gain Vary

$f=960 \mathrm{~Hz}($ eq $2 \mathrm{BPF}$ * $=1800)$

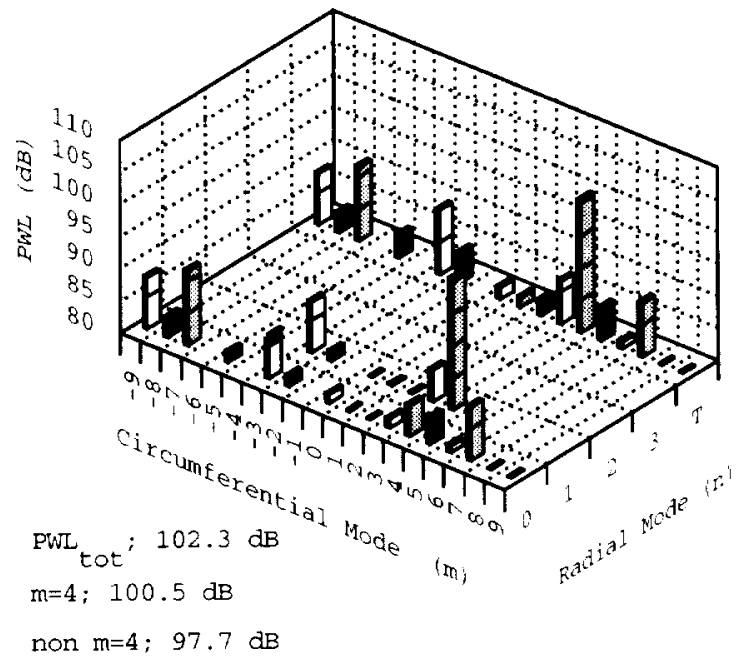

b) Amplifier Gain $=0.50$

Figure 8. Combined Actuator Signatures in Exhaust 
NASA ANCF 48" Fan Mode Power Levels

28 vanes @ $2.25 " * 2 \mathrm{BPF} * \mathrm{C}_{\mathrm{C}}=1800$

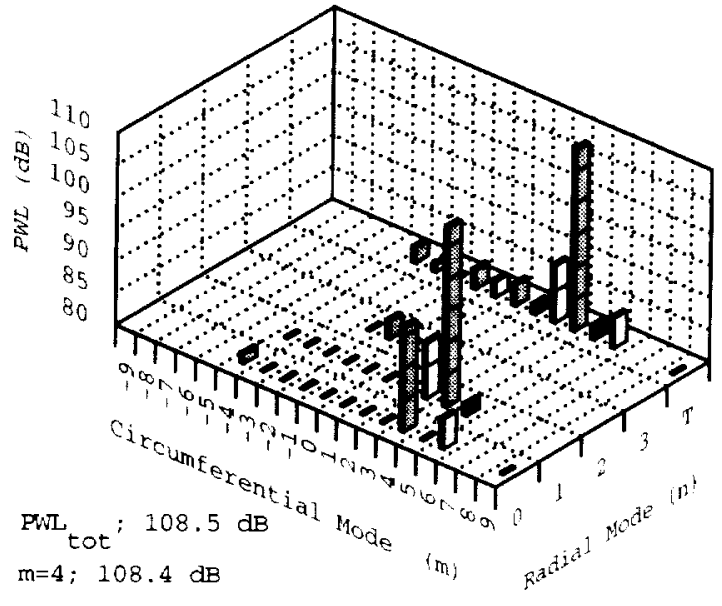

non $\mathrm{m}=4 ; 93.7 \mathrm{~dB}$

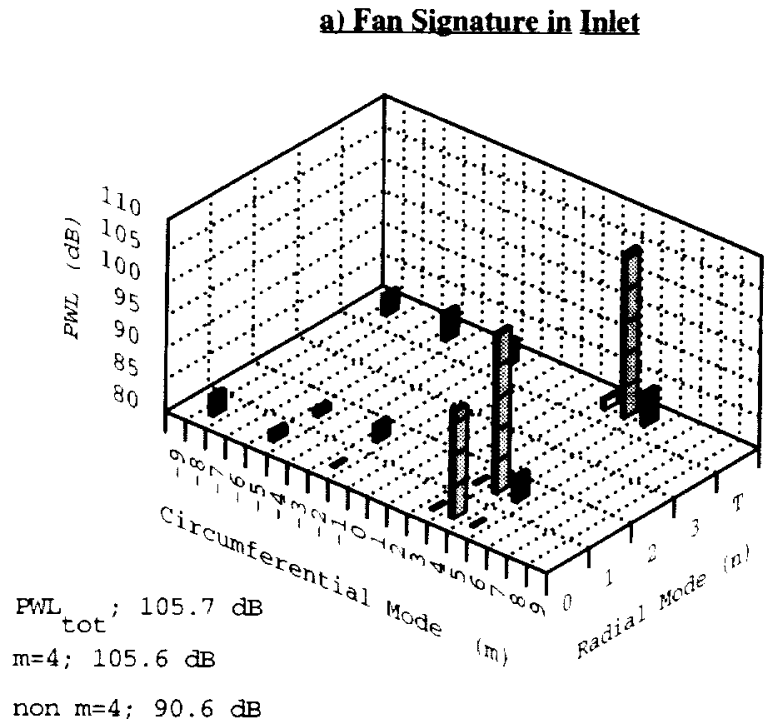

c) Fan Signature in Exhaust

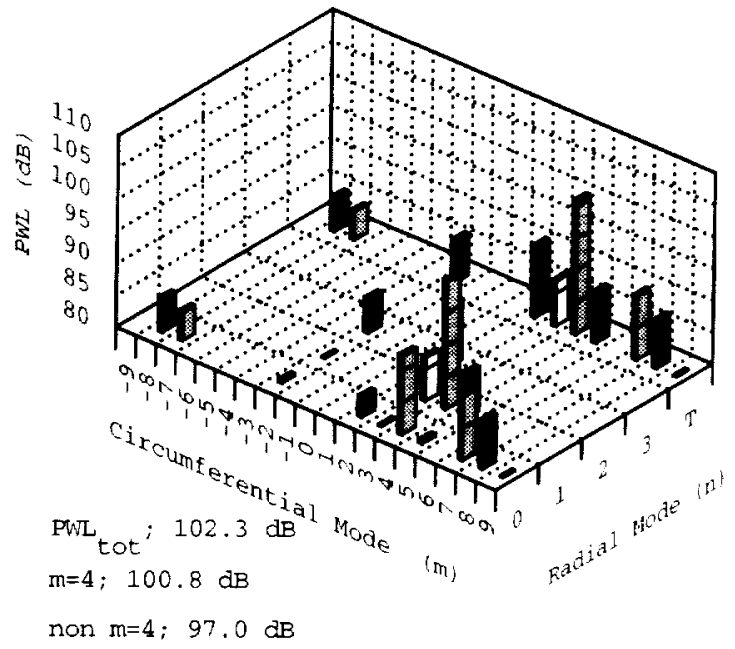

b) ANC On Signature in Inlet

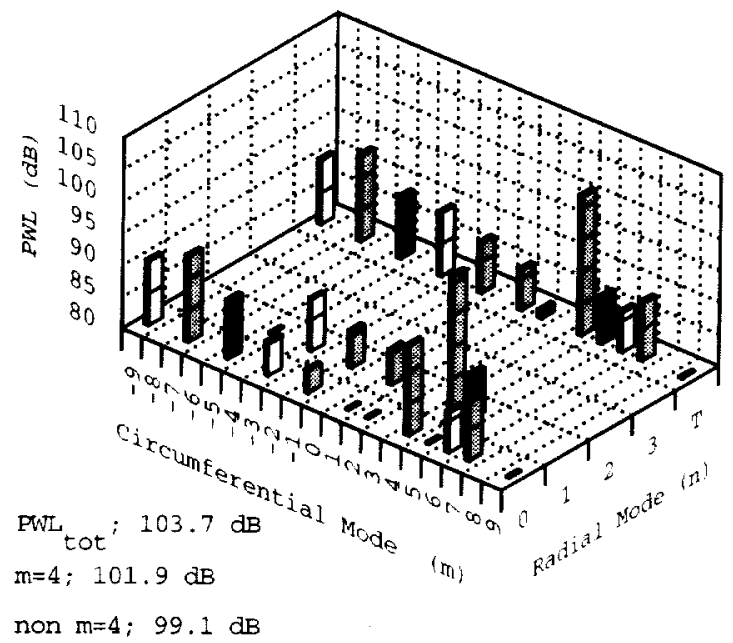

d) ANC On Signature in Exhaust

Figure 9. Performance of ANC System at 1800 RPM 


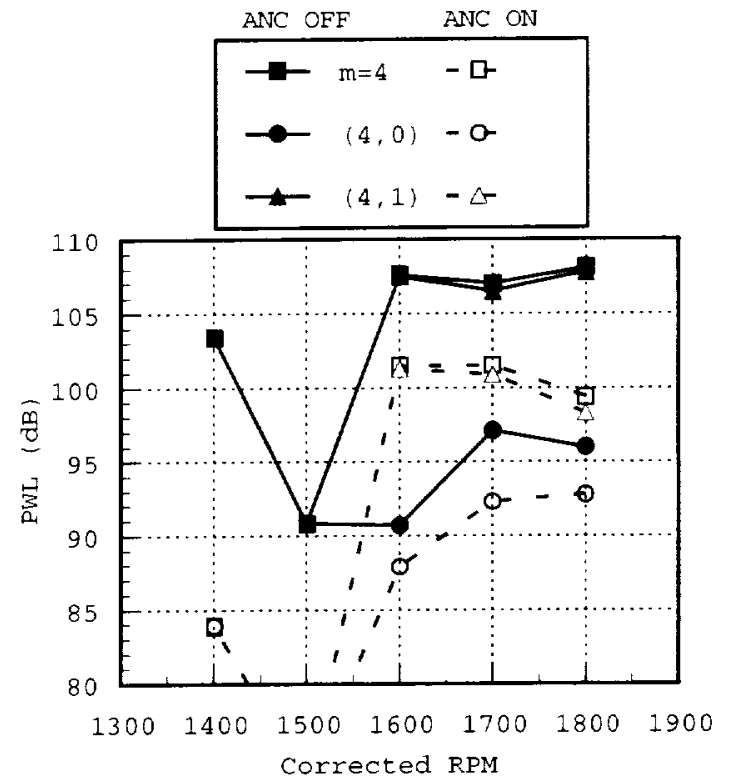

a) Mode 4 Absolute Levels

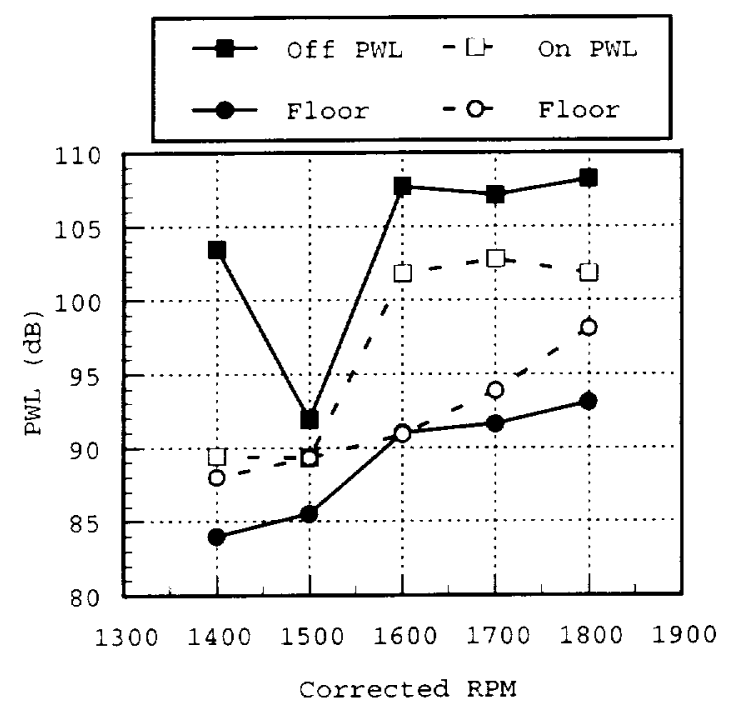

c) 2BPF Absolute Levels

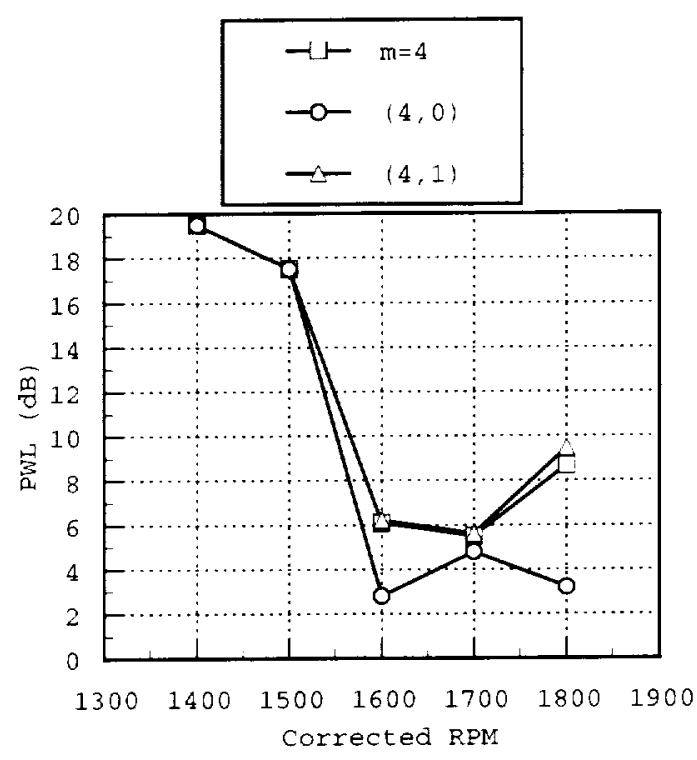

b) Mode 4 Reduction Achieved

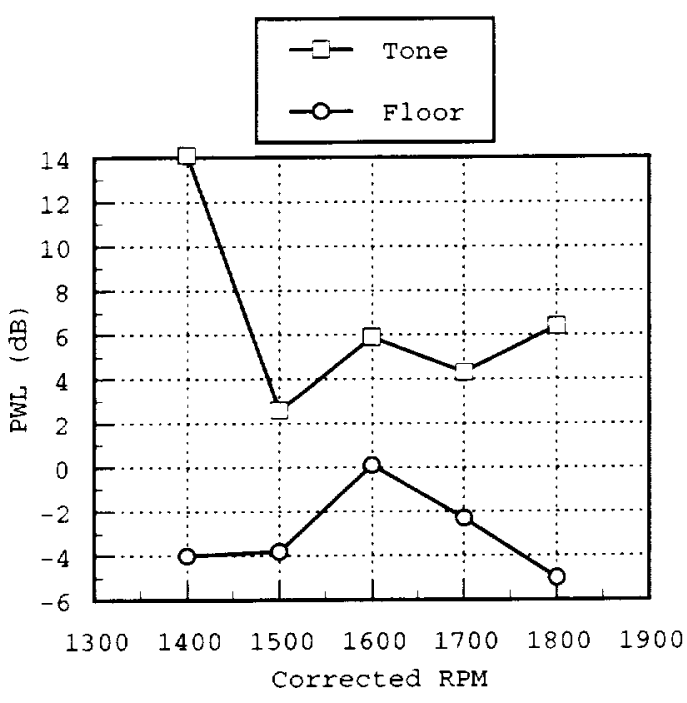

d) 2BPF Reduction Achieved

Figure 10. ANC System Performance in Inlet vs RPM 


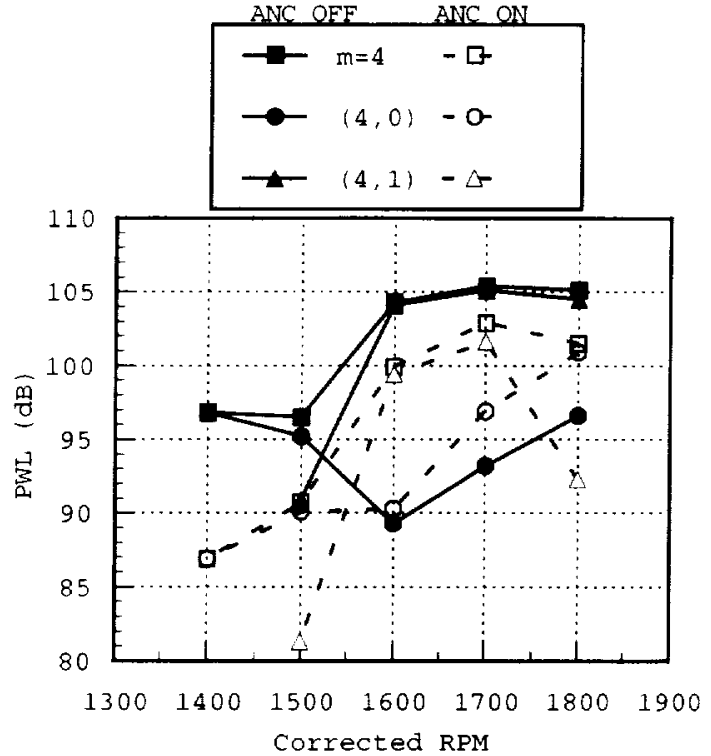

a) Mode 4 Absolute Levels

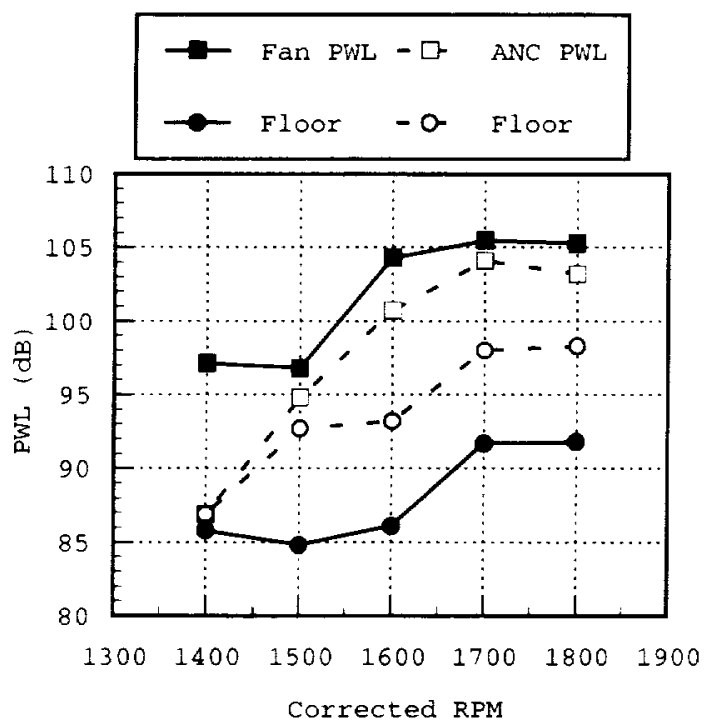

c) 2BPF Absolute Levels

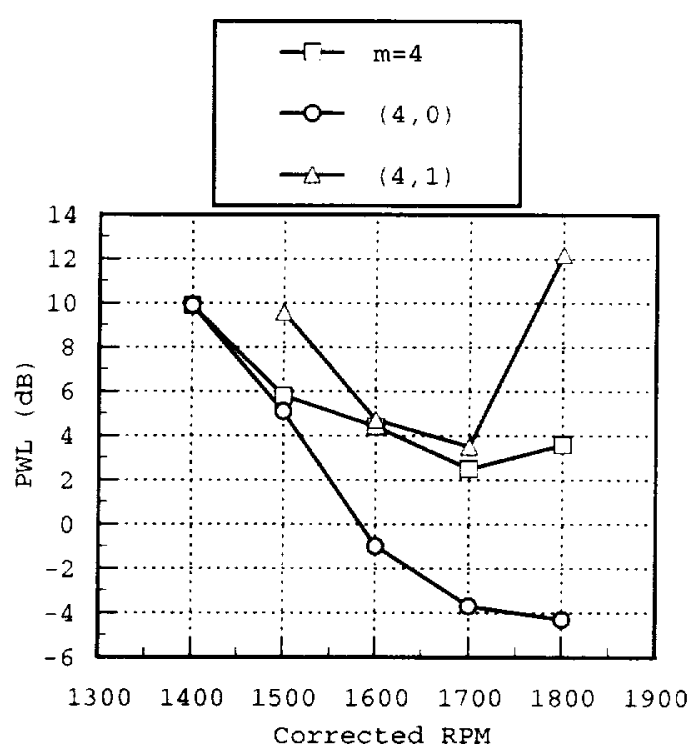

b) Mode 4 Reduction Achieved

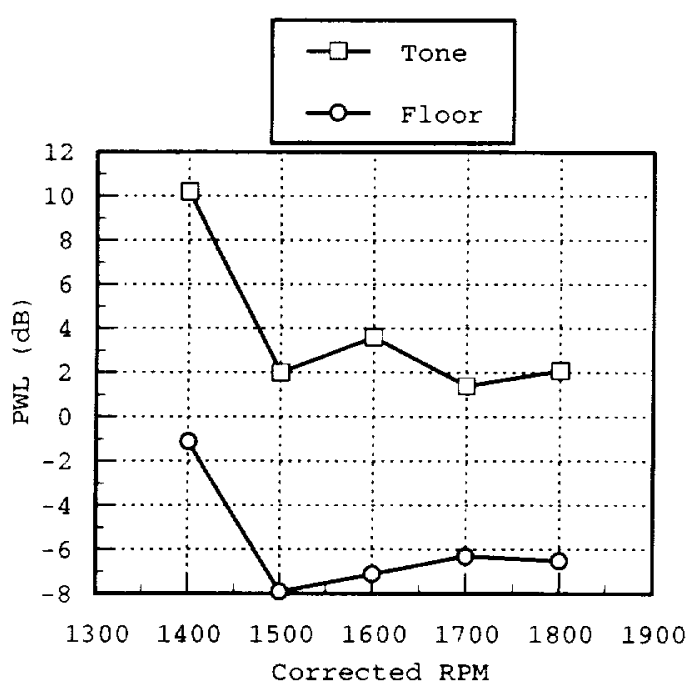

d) 2BPF Reduction Achieved

Figure 11. ANC System Performance in Exhaust vs RPM 

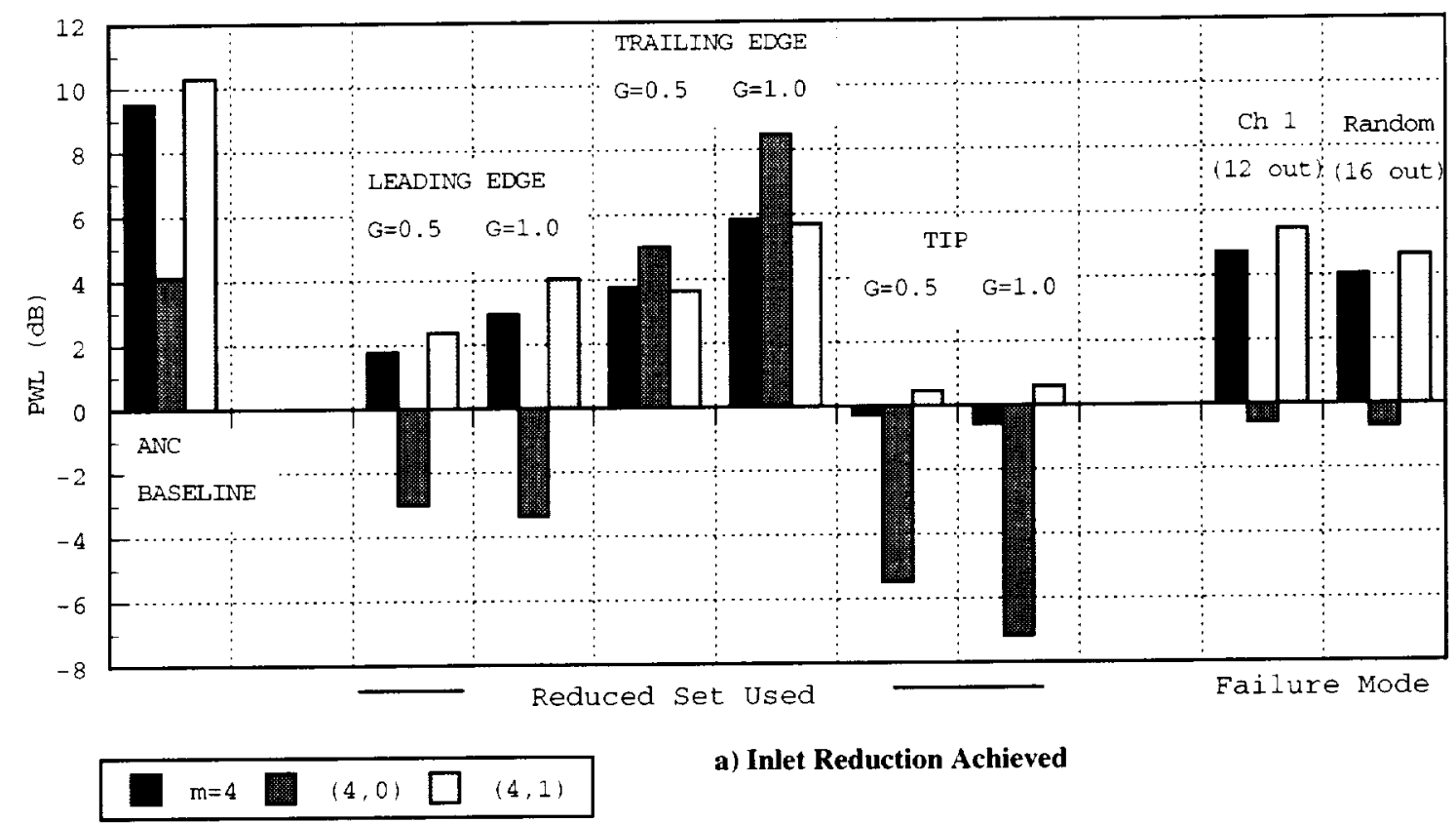

a) Inlet Reduction Achieved

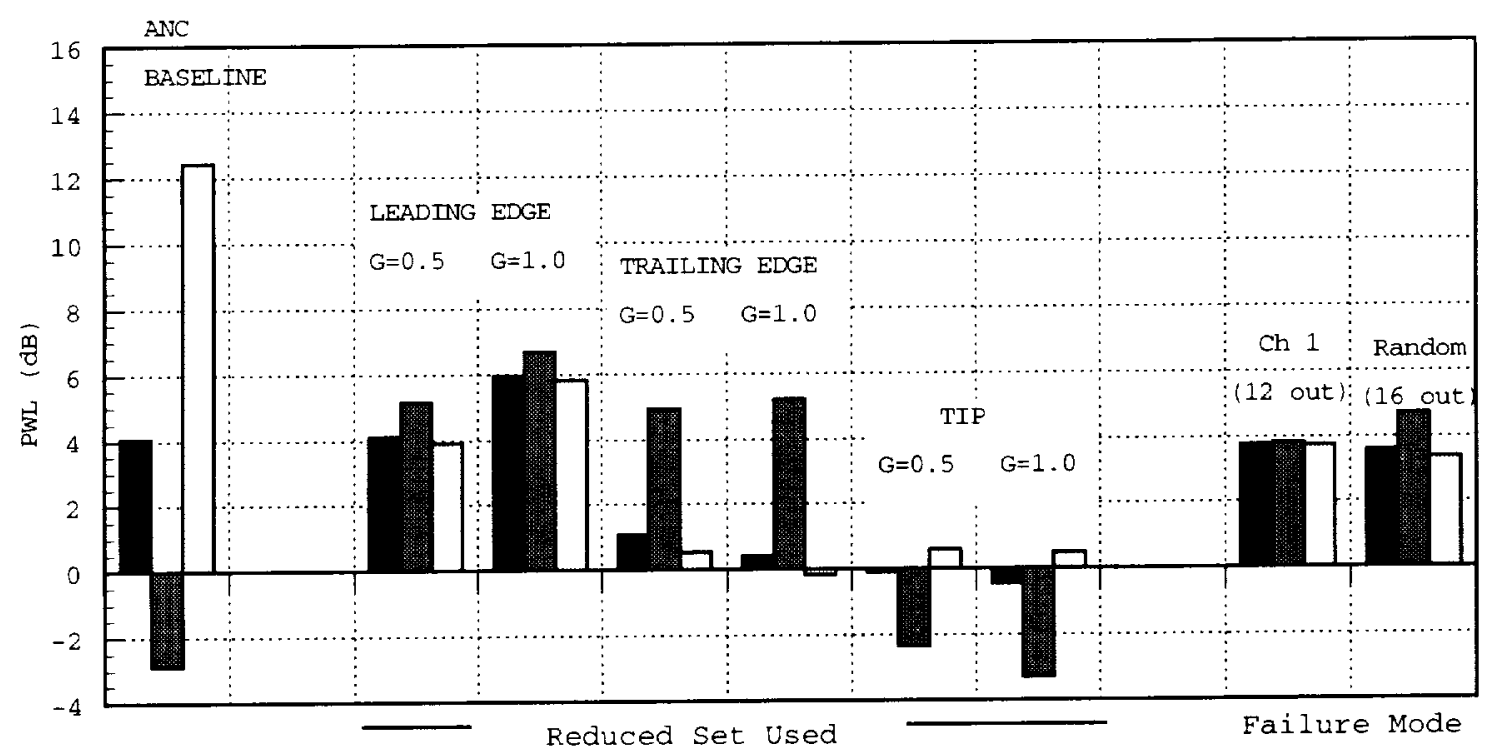

b) Exhaust Reduction Achieved

Figure 12. Effect of Reduced Complexity/Failure on ANC Performance at 1800 RPM 


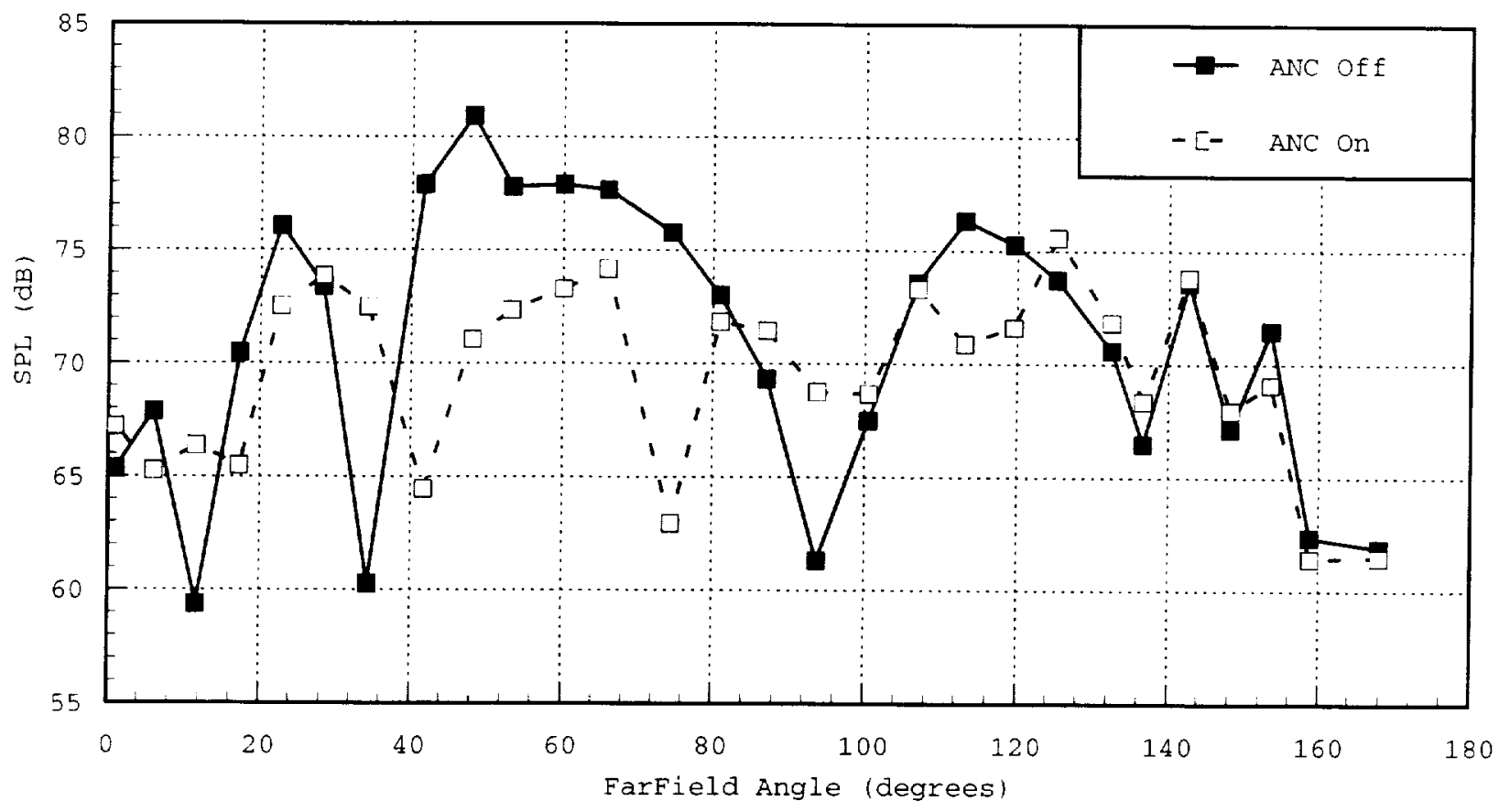

Figure 13. Farfield ANC Directivity at 1800 RPM

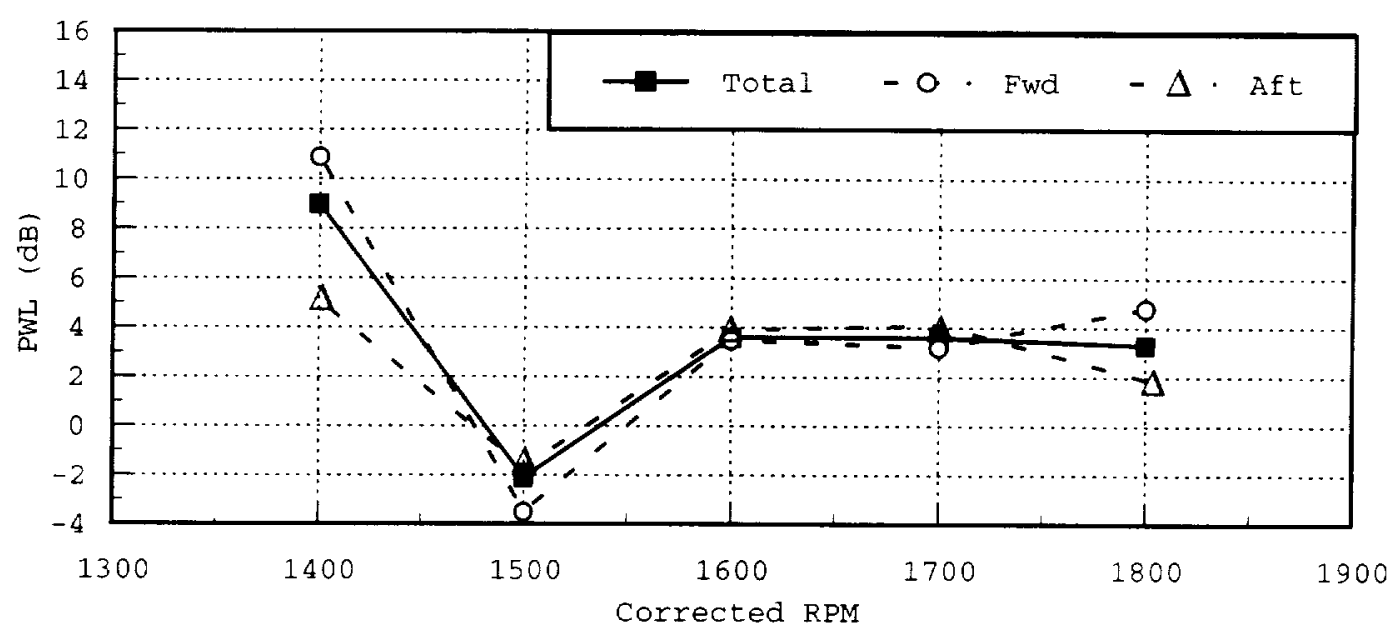

Figure 14. Farfield ANC Performance vs RPM 



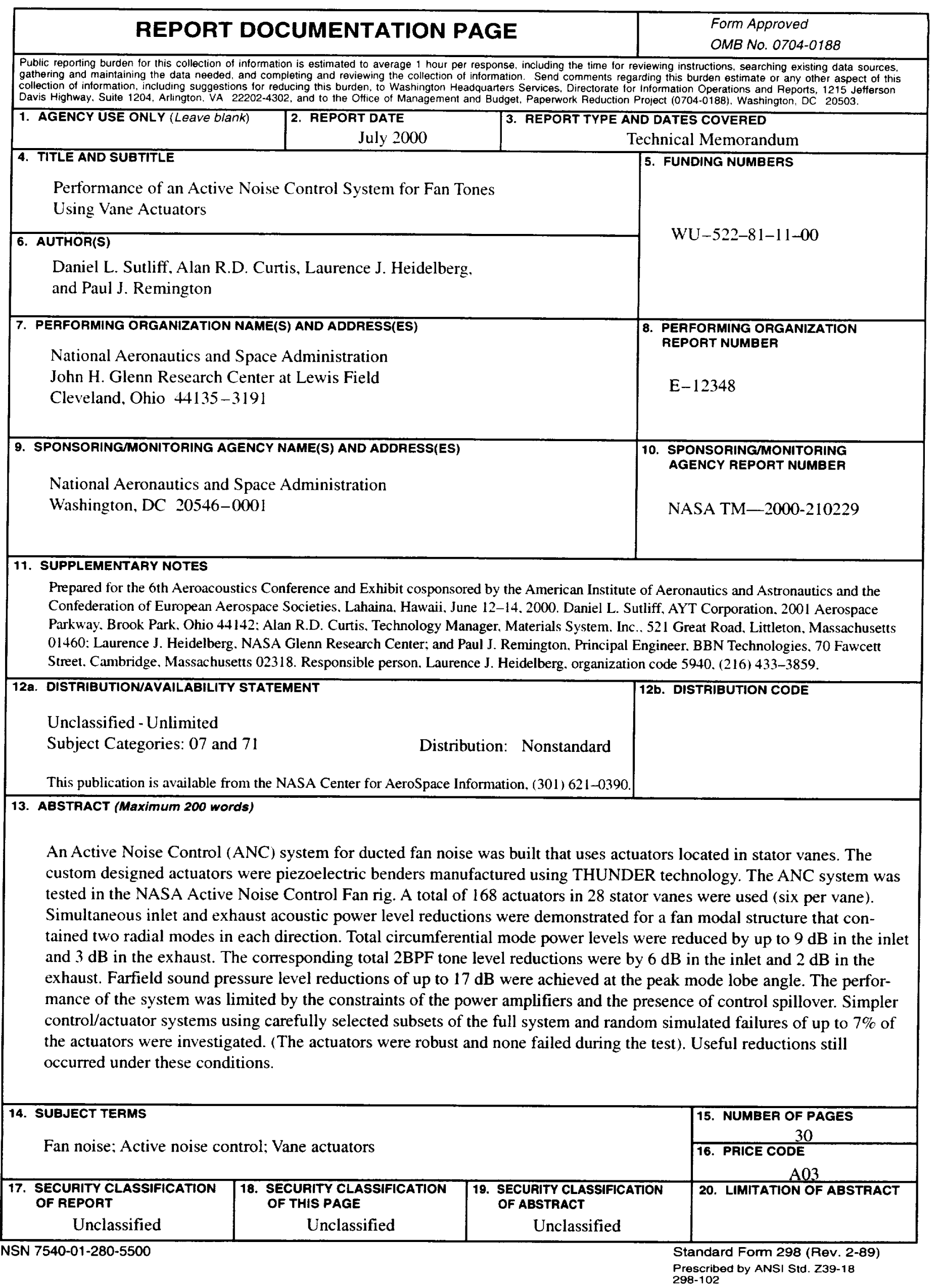





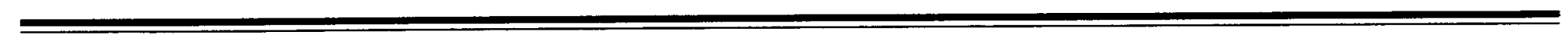

